\begin{tabular}{|l|l|l|l|l|l|}
\hline MUNIBE Antropologia-Arkeologia & $n^{\circ} 72$ & $219-237$ & DONOSTIA & 2021 & ISSN 1132-2217 • eISSN 2172-4555 \\
\hline
\end{tabular}

\title{
El marcado de ganado ovino roncalés: análisis de un discurso etnológico e ideográfico
}

\author{
The livestock branding of sheep in the roncal valley: \\ analysis of its ethnological and ideographic discourse
}

\author{
PALABRAS CLAVES: Pirineos, Derecho consuetudinario, Cultura pastoral, Lenguaje ideográfico, Ideogramas. \\ GAKO-HITZAK: Pirinioak, Ohiturazko Zuzenbidea, Artzain-Kultura, Hizkuntza Ideografikoa, Ideogramak. \\ KEY WORDS: Pyrenees, Customary law, Pastoral culture, Ideographic language, Ideograms.
}

Pablo M. ORDUNA PORTÚS ${ }^{(1)}$, Ángel María PÉREZ ARTUCH ${ }^{(2)}$

\section{RESUMEN}

Este estudio analiza el mensaje etnocultural trasmitido a través de los diferentes sistemas de marcaje que son empleados en las cabañas ganaderas del Valle de Roncal. Para ello, se ha realizado un trabajo de campo estructurado en una metodología de encuestación y registro tanto de los ideogramas de cada marca ganadera como de sus imágenes fotográficas en caso de aún conservarse la herramienta pecuaria. Se ha efectuado una investigación no experimental, que consta de un estudio descriptivo a través de un cuestionario analítico centrado en el tipo de ganado y modelo de explotación, el dibujo y significado de marca y el sistema de marcaje. A continuación, en el análisis correlacional de los resultados obtenidos, se evalúa el componente etnológico que aporta el discurso gráfico y su significación en la comunidad, más allá del propio objeto inicial agropecuario.

\section{LABURPENA}

Ikerketa honek Erronkariko etxoletan erabiltzen diren xaki-sistemen bidez helarazitako mezu etnokulturala aztertzen du. Horretarako, landa-lan bat egin da inkestatzeko metodologia batean egituratuta. Abeltzaintzako marka bakoitzaren ideogramak eta haien argazki-irudiak erregistratu dira. Ikerketa ez-esperimental bat egin da eta azterlan deskribatzaile bat du. Azterlana ganadu mota eta ustiapen-eredua, markaren marrazkia eta esanahia eta markatze-sistema ardatz dituen galdetegi analitiko baten bidez bideratu da. Jarraian, Iortutako emaitzen analisi korrelazioan jarriz, diskurtso grafikoak dakarren osagai etnologikoa eta komunitatean duen esanahia ebaluatzen dira, nekazaritza eta abeltzaintzako hasierako objektutik harago.

\section{ABSTRACT}

This study analyzes the ethnocultural message transmitted through the different marking systems that are used in the cattle ranches of the Roncal Valley, a Pyrenean enclave in Navarra. For this purpose, a structured field work has been carried out in a methodology of survey and registration of both the ideograms of each livestock brand and its photographic images in case the cattle tool is still preserved. Initially, a non-experimental research has been carried out consisting of a descriptive study through an analytical questionnaire focused on the type of livestock and model of exploitation, the design and meaning of the brand and the marking system. Then, in the correlational study of the results obtained, the ethnological component that the graphic discourse provides and its significance in the community is evaluated. This language is evaluated beyond the initial livestock objective itself. In conclusion, is obvious that the formation of this symbolic code is the expression of a multi-secular belonging of the home as an institution to a community group. This is one more example of its differentiated as legal figure rank in the common local law and social order structure.

Even so, in the Roncal Valley, the social value of the practice of branding in a bunch is old and remains visible. Such the trace of them has also been indicated in the cultural landscape through different handmade elements. At the same time, the memory of different mark methods is maintained. Although, it is important to mention that some of the branding techniques were abandoned. In addition, part of a traditional knowledge linked to an old skill and a way of interacting inside the customary law was losing. In short, then the mark ritual had already become a new technical figure away from the traditional model.

\footnotetext{
(1) Basque Culinary Center (Mondragon Unibertsitatea). C/ Mayor 25, $3^{\circ}$ Izq. 31600 Burlada, Navarra. Mail: porduna@bculinary.com

(2) Proyecto Bidankozarte Ekimena. Mail: bidankozarte@yahoo.es
} 


\section{INTRODUCCIÓN}

Es cierto que hoy el acceso al valle roncalés sigue suponiendo atravesar angostos pasos por foces e intrincados puertos de montaña. Sin embargo, el antiguo aislamiento que cerraba esta comarca durante los largos meses de invernada ya es un capítulo cerrado en la cotidianeidad de sus gentes. En la actualidad el tránsito es sencillo en automóvil, y las labores del campo, al igual que la propia climatología, se han suavizado en sus extremos y dureza. Ahora bien, esto no significa que la singularidad de sus gentes y gran parte de su tesoro patrimonial de corte etnológico y agropecuario no se haya mantenido. Éste es el caso en muchos usos vivenciales $\mathrm{y}$, al menos, dentro del conocimiento tradicional, que sigue trasmitiéndose a sus generaciones más jóvenes.

Un ejemplo de esta trasformación acaecida es la modelación de los usos y manejos del ganado. La costumbre había asentado una cultura pastoral trashumante que sabía aprovechar los pastos de los puertos en verano y las estepas semiáridas de la Ribera en invierno (Orduna y Orduna, 2019; Sardaña y Reiné, 2009: 4041; Fillat, 2008). Poco a poco, ésta ha cedido espacio a explotaciones más pequeñas en número de cabezas de ganado y de tipo semiestabulado. Los rebaños que imperaban en el paisaje natural y cultural roncalés eran los ovinos, aunque hoy en día comparten escenario con el caballar y las reses vacunas destinadas a carne.
Ante estos cambios, se hace más que necesario un trabajo de campo que permita recoger aquellos testimonios etnográficos de una cultura tradicional ganadera en desaparición. De esta manera, en el presente estudio se ha planteado como objetivo principal el registro e interpretación del sistema de marcaje del ganado ovino. Éste es un modelo que trasciende lo meramente agropecuario y se inserta de forma precisa y activa en la constitución del discurso cultural de sus gentes, como un elemento proactivo más dentro de los códigos normativos de su derecho consuetudinario. Es ésta una normativa que regula el significado del signo, pero también el uso del espacio y sus recursos [Fig. 1].

Sánchez y Rodríguez (2014: 179) señalan que «la identificación animal es importante para la correcta aplicación de medidas orientadas a la prevención y el control de crisis agroalimentarias que podrían estar originadas en las condiciones de salud en los animales destinados para el consumo». En este sentido se refieren al control actual de la trazabilidad del espécimen desde su origen a su destino final alimentario. Éste es un requisito exigido en general por la comunidad internacional. De hecho, en diversos países constituida esa marca (a fuego o electrónica) queda registrada ante las autoridades de la región con el fin de ejercer ese control. Así, en Colombia, este ente se denomina Registro de Hierro Quemador. Pero tal afán de control viene de antiguo. Y, por ejemplo, en la Extremadura

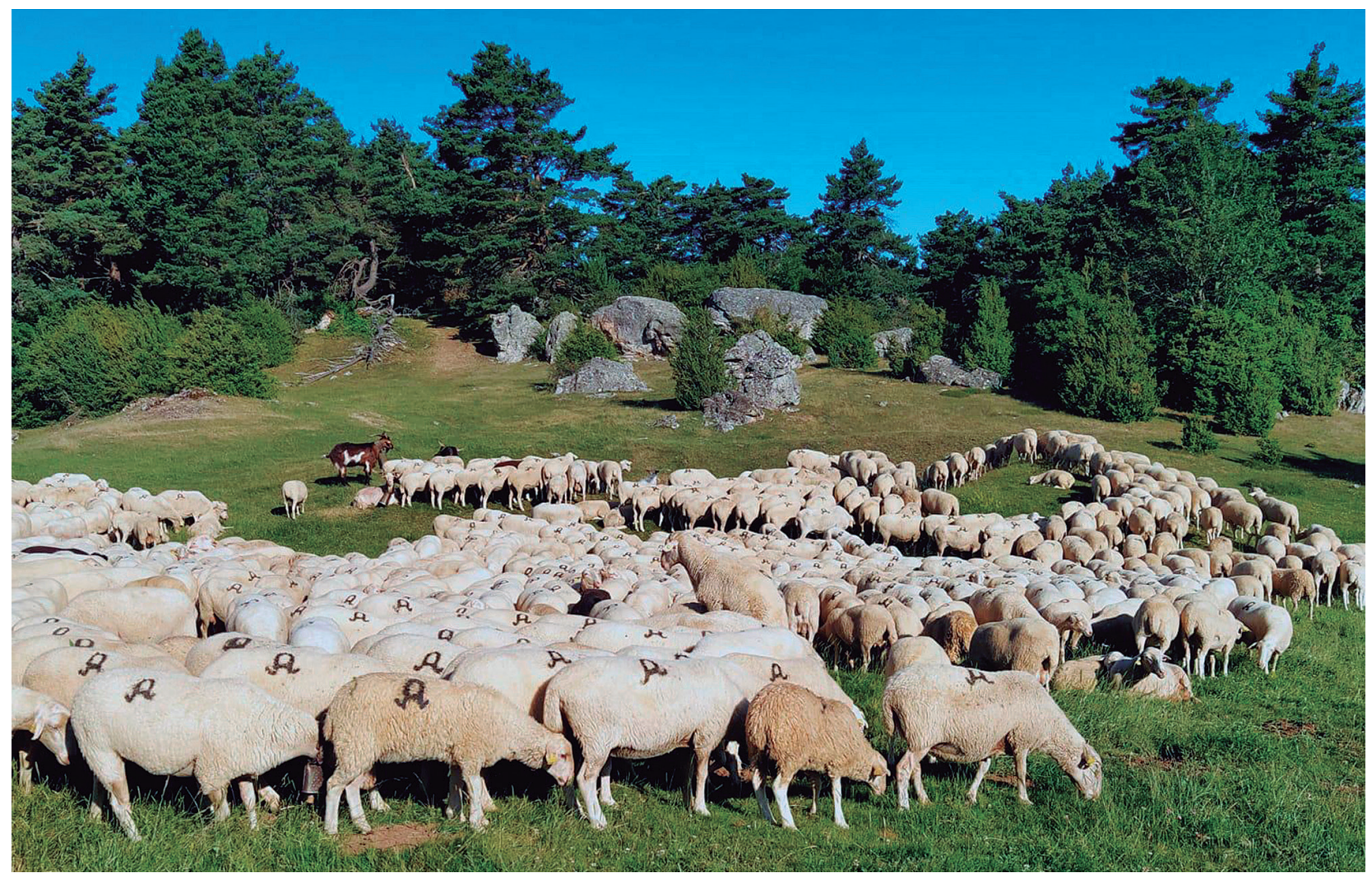

Fig. 1. Rebaño de Casa Arguedas (Vidángoz) pastando en los puertos comunales del valle. / Herd of Casa Arguedas (Vidángoz) grazing in the communal passes of the valley. Fuente: Equipo de campo. 
del Ochocientos, la ganadería asnal, mular y caballar estaba bien regulada en su cría y comercio «mediante la creación de la Junta de Caballería del Reino y el establecimiento de registros anuales y obligatorios [...]. Estas marcas o yerros sirvieron en muchas ocasiones incluso como firma de los propietarios que no sabían escribir» (González Solís, 2018: 237). Es más, en la Ciudad de México, dentro del virreinato de Nueva España, se pueden rastrear hasta sus orígenes españoles a 155 propietarios de ganado ovino o bovino gracias al registro de sus marcas en la Mesta (Butzer, 1988: 34).

En el caso roncalés, y navarro en general, tal trámite se deriva al registro de explotaciones y cabezas ganaderas que hace el Gobierno de Navarra. De esta manera, se vuelca la información en una base estatal denominada Sistema Integrado de Trazabilidad Animal (SITRAN). Ésta integra el Registro General de Explotaciones Ganaderas (REGA), el Registro de Identificación Individual de Animales (RIIA) y el Registro de Movimientos (REMO).

Sin embargo, en Roncal, a nivel tradicional, las casas sí registraban sus marcas en los ayuntamientos de cada una de las siete villas del valle. En esta cultura pastoril ese marcado representaba algo más holístico, que trascendía lo meramente agropecuario. El empleo de la marca de la casa no significaba sólo herrar o empegar con pez al animal, sino que también podía derivarse en señalar la propiedad sobre diferentes objetos. A su vez, su uso determinaba un código ideográfico que establecía la personalidad propia de la casa como institución en el conjunto de la comunidad del pueblo, del valle e incluso en las tierras de pastoreo de los inviernos cabañeros por el mediodía navarro junto al Ebro. Misma filiación entre marca y casa se da a nivel simbólico en la vertiente francesa del Pirineo (Campello y Péquignot, 2021: 31).

Es por ello que se puede decir que este hecho no es exclusivo de esta comarca y que está presente en la vertiente norte de la cordillera pirenaica y en espacios geográficos mucho más distantes donde, según Étienne Landais (2000: 354), "l'importance de la conservation des marques à travers leur transmission d'une génération à l'autre dans les sociétés pastorales traditionnelles est directement liée au fait que celles-ci sont pour la plupart des sociétés segmentaires, dans lesquelles les règles de filiation, de résidence et d'union matrimoniale conduisent à la scission des structures lignagères en éléments emboîtés, de la tribu à la famille nucléaire en passant par différents types de segments de lignage (fractions, clans, etc.) pour lesquels aucune nomenclature de portée générale ne s'est imposée."

Como ejemplo de la relevancia que tenían las marcas en su identificación en el valle a estudio, se puede exponer un brote de viruela ovina que tuvo lugar en el verano de 1940. Debido a ello, se procedió a confinar por un tiempo y vacunar a los ganados. Con tal fin, el inspector municipal de higiene y sanidad pecuaria procedió a relacionar: el número de cabezas de cada reba- ño, el monte o término en el que se encontraban e iban a ser confinadas, el dueño de las ovejas y las marcas de pez que llevaban las mismas. En esa misma década (1940-1950) se comenzaron a registrar los diferentes tipos de animales en los libros denominados Registro especial de ganados. En ellos ya se recogen muchas de las marcas de pez de manera más o menos sistemática.

Como señala un proverbio roncalés, göarpenari ez zau akabatan tenpra [a la memoria no se le acaba el tiempo] y a cada cual no debe olvidársele a quién y qué pertenece. Por ello, ha de analizarse este tema, tan poco estudiado en la bibliografía científica de corte etnológico, con objeto de apoyar la conservación de este acervo pastoril en vías de desaparición.

\section{MATERIAL Y MÉTODO}

\subsection{Encuadre geográfico y humano}

El Valle de Roncal es el territorio más oriental del Pirineo en Navarra y se halla vertebrado por el cauce del río Ezka. Este cauce sirve de nexo de siete villas que de norte a sur se distribuyen conformando el territorio. El valle está dividido en ayuntamientos bajo la ordenación de una Junta General gobernadora de la mancomunidad supramunicipal (Orduna, 2011). Por otro lado, sus rasgos climatológicos y de altitud han marcado en gran medida la personalidad ganadera trashumante y, a la vez, semi autárquica de la comarca (Orduna y Orduna, 2019).

Desde el punto de vista etnográfico, se trata de una comunidad perteneciente al conjunto de pueblos que se han venido a denominar como 'culturas de frontera'. A la par, presenta determinantes intrínsecos de los diferentes valles de ambas vertientes del Pirineo. Son marcadores relativos a la organización del territorio, las estructuras sociales y familiares o los rasgos propios del derecho consuetudinario (Comas, 2015: 16-17). En definitiva, es una sociedad pirenaica que a pesar de los rigores climáticos no se mantuvo aislada en la cordillera.

\subsection{Sistema ganadero pirenaico: trashumante - estabulado}

En la sociedad roncalesa este modelo ganadero trashumante se constituyó como el primer sector productivo hasta el último tercio del siglo XX. La explotación del ganado ovino ofrecía grandes rendimientos a la economía local, que eran complementados con la industria maderera, cabañas menores de bovino y equino y una agricultura autárquica de subsistencia. Es verdad que en el último tramo del siglo pasado ese protagonismo fue usurpado poco a poco por el sector servicios y de turismo. Sin embargo, aún se puede decir que su presencia es más que importante. Como en otras partes del Pirineo, supone la actividad humana que más contribuye a modelar el paisaje cultural local (Fernández de Larrinoa, 2009; García y Lasanta, 2018). 
Como se señalaba, la explotación pecuaria se ha centrado en el ganado ovino seguido por el bovino y equino con destino a la producción de carne. En cuanto al primer grupo, se trata de rebaños de ovejas con escasa presencia de machos cabríos-txotos-, empleados para dirigir al conjunto en la trashumancia. Si antes los ciclos climáticos según las invernadas y el estío obligaban a los productores extensivos a descender hasta las Bardenas, hoy en día esta es una práctica que se va desvaneciendo. En la actualidad, comienzan a imponerse explotaciones ovinas semiestabuladas que en los meses de otoño a primavera resguardan sus rebaños en naves o bordas -corraliza, corral, rancho- sitas en los fondos de valle. Por otro lado, aunque la mayor parte de las cabezas de ganado siguen siendo de raza rasa navarra, se observa la paulatina introducción de otras, como latxa, lacaune o assaf, con objeto de aumentar la producción láctea con destino a las queserías locales.

\subsection{Trabajo de campo y gabinete}

Existen dos dificultades a la hora de abordar cualquier investigación antropológica: una conceptual y otra metodológica. La primera obliga al etnólogo a precisar la noción de medio natural como lugar no sólo de laboreo sino también de encuentro sociocultural. Por ello, antes de abordar el trabajo de campo es necesario delimitar y aclarar el concepto de 'marca ganadera', 'mensaje ideográfico' y 'significado colectivo e individual del símbolo'. La segunda dificultad es de carácter metodológico y obliga a precisar la forma en que se han de observar de forma cualitativa las pautas agropecuarias. Para ello se efectuó una encuesta-modelo semiestructurada y abierta acompañada de una observación participante (Vargas, 2012; González Díaz, 2014).

El trabajo de campo se desarrolló entre 2018 y 2020. Éste fue seguido de un análisis de gabinete que se extendió comenzando de forma previa a acabarse el trabajo sobre el terreno en 2020. La revisión de información de datos relativos al ganado lanar concluyó en abril de 2021. Sin embargo, en prospectiva está abierta la posibilidad de completar este estudio en el Valle de Roncal con la ampliación de análisis a los ganados bovino y equino que, si bien tienen menor peso en la cabaña local, si tuvieron sus propias formas de marcaje. Por otro lado, es pertinente tener en cuenta que se puede profundizar aún más en el análisis de otras marcas de propiedad relativas a la industria maderera y gestión forestal tradicional del enclave pirenaico en cuestión.

Entre los informantes se entrevistó a un total de 61 personas pertenecientes a las diferentes villas. Es significativo el escaso número de población menor de 50 años que tiene conocimiento alguno sobre este sistema de marcas. De número global de fuentes orales sólo 10 eran menores de ese rango etario. Así el 84\% de los informantes tenía más de 50 años, y de este porcentaje el $60 \%$ más de 70 años. La diferencia de encuestaciones entre hombres y mujeres posicionaba en un 30\% de féminas frente al $70 \%$ masculino.

Es reseñable que no se pudieron grabar las entrevistas por efectuarse estas mientras se ejercían labores agropecuarias por los entrevistados o por el rechazo de algunos de ellos a que sus informaciones quedarán registradas en audio. Atendiendo a su edad avanzada, se buscó establecer entrevistas no estructuradas. Así se evitó enfrentar al dialogante a una batería cerrada de preguntas que pudiera predisponer a su rechazo (González, 2019: 16). Esto permitió establecer una honesta 'reconstrucción de una parte del paisaje', cultural y agropecuario no forzada o encasillada en una diapositiva fija del mismo (Sabaté, 2008: 22) [Figs. 2 y 3].

Encuestados por localidad

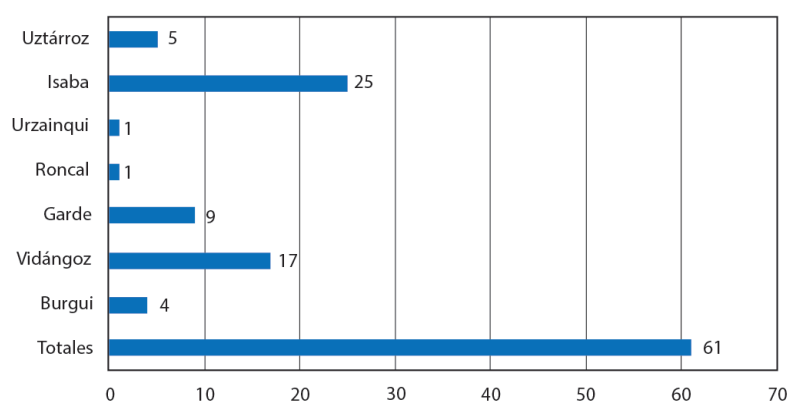

Fig. 2. Número de encuestados por población de origen. / Number of respondents by population of origin. Fuente: Elaboración propia.

Tipología de encuestados

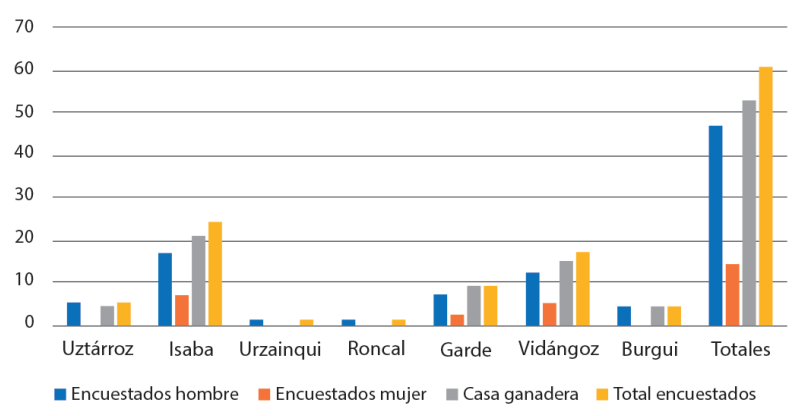

Fig. 3. Tipología de encuestados por municipio. / Type of respondents by municipality Fuente: Elaboración propia.

\section{CONCEPTOS DE MARCA Y POSESIÓN}

La marca como tal es simplemente un signo distintivo. En su conjunto, pueden ser temporales o permanentes atendiendo al tiempo en que persistan en el cuerpo del animal a lo largo de su vida. Entre las primeras se encuentran las accidentales empleadas en una circunstancia muy concreta (enfermedad, separación del resto del rebaño...) de corta duración. Incluso entre estas no permanentes pueden diferenciarse las fijas, 
$\Delta^{\mathrm{P}}$ 
En el valle navarro, esta práctica de marcaje de diferentes útiles domésticos (cestas, mobiliario, mangos), aperos de labranza (kañablak -collarones de cencerros-, sardes, yugos, astraletas -hachas-, etc.) o incluso sombreros del traje tradicional, era un hecho habitual. Así lo han reflejado diferentes informantes actuales al igual que lo apuntaba a comienzos de siglo XX Bernardo Estornés (1930: 408 y ss.). En los años treinta de la pasada centuria el estudioso local describía diferentes utensilios de madera y motivos pastoriles dibujados en o por ellos. Entre tales recogía la costumbre de imprimir, con una herramienta fabricada en madera de boj, la señal ganadera de la casa sobre las hogazas propias del horno vecinal a modo de 'marca de pan': símbolo de propiedad y de continuidad vital de supervivencia [Figs. 6 y 7 ].

Ya se señaló cómo Ariznabarreta (1991: 145) ha detectado en el caso de El Pueyo de Jaca que este hecho trasciende lo terrenal hasta una dimensión de corte espiritual y religiosa. En ese sentido detecta que las marcas de ganado de las casas «coinciden con las de las sepulturas del interior de la iglesia. [...] Cada sepultura lleva tallada rudimentariamente la marca de la casa sobre la tapa de madera». Por otra parte, Violant i Simorra (1997: 410-412) señala cómo en zonas del Pirineo se adornaba con filigranas de la pez diferentes partes del cuerpo de los carneros. Sobre todo, esto se ejercía sobre los 'esquileros' o portadores -junto a los txotos de los metales más sonoros-. Según el estudioso catalán, era una forma proteger, tipo amuleto, a los animales de cualquier espíritu maligno o adversidad. En Roncal, el etnógrafo catalán no constata tal práctica y afirma que sólo se les distinguía por el tipo y gran tamaño del cencerro que portaban.

Ahora bien, aunque no se han recibido datos de los informantes referentes a una costumbre igual o similar, sí se han detectado otras prácticas de tipo inmaterial donde el anagrama de la marca toma un papel protagonista. Se ha identificado un uso gráfico que trasciende lo meramente utilitarista a nivel material. En algunas familias se ha visto la marca propia de la casa expuesta en elementos de relevancia significativa para la misma a nivel identitario. Así, por ejemplo, en Vidángoz, en el Corral de Diego la encontramos dibujada en un adorno de pared que representa un cordero, decoración que se repite en la fachada de Casa Mastuzarra en Burgui. En la Casa Ezker de Garde la señal está labrada en su puerta de madera sobre la figura de un pastor. En Uztárroz, también se representa la marca de la casa Krutxaga en su borta -puerta de entrada al inmueble-. Hay que señalar que el portón de esta casa está decorado con multitud de imágenes de tipo etnográfico y espiritual representando situaciones propias del calendario laboral y religioso tradicional [Figs. 8, 9 y 10].
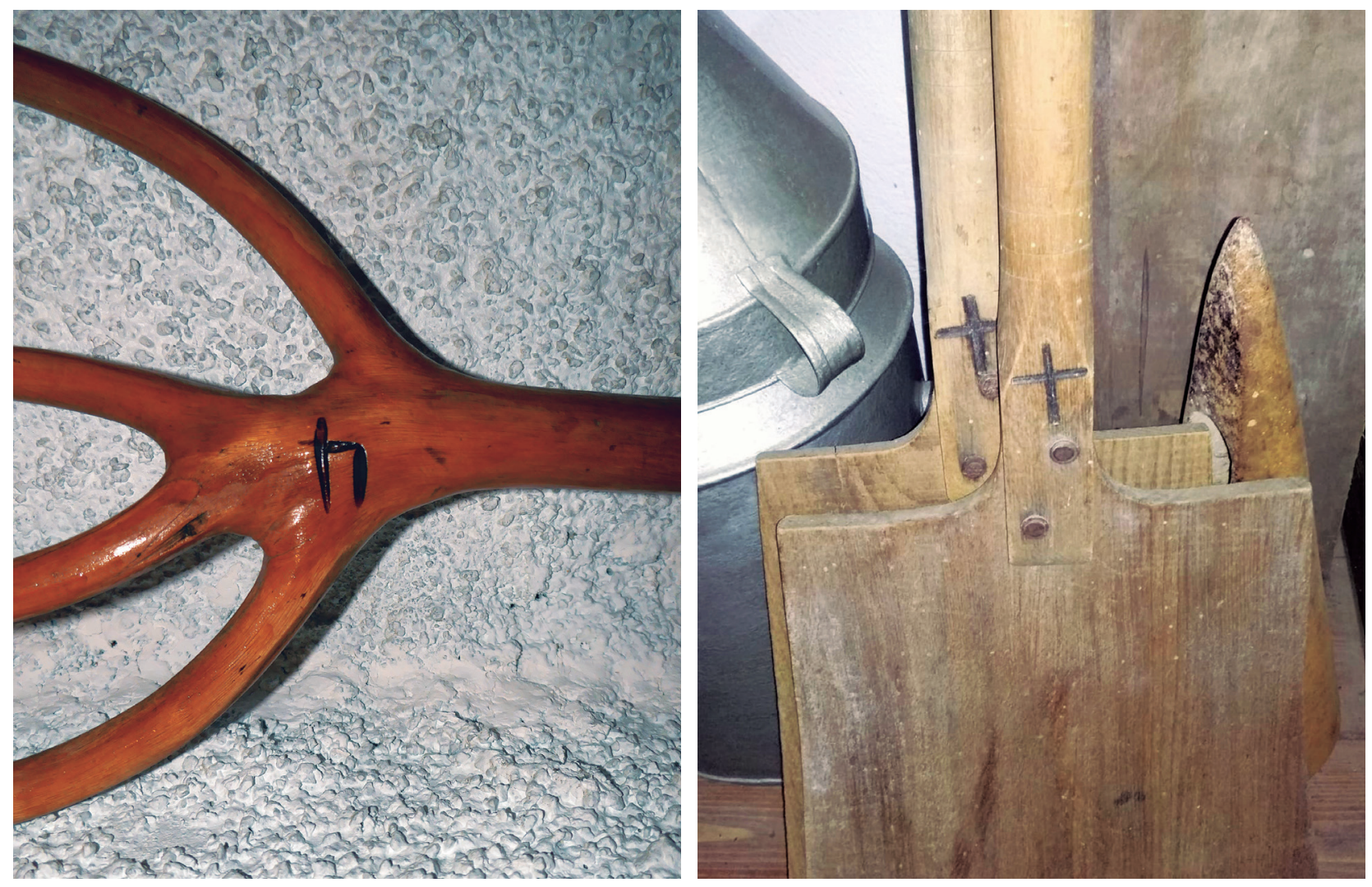

Figs. 6-7. Marcas de diferentes casas grabadas a fuego en un sarde y unas palas de horno. / Marks of different houses engraved by fire on a sarde and some oven shovels. Fuente: Equipo de campo. 


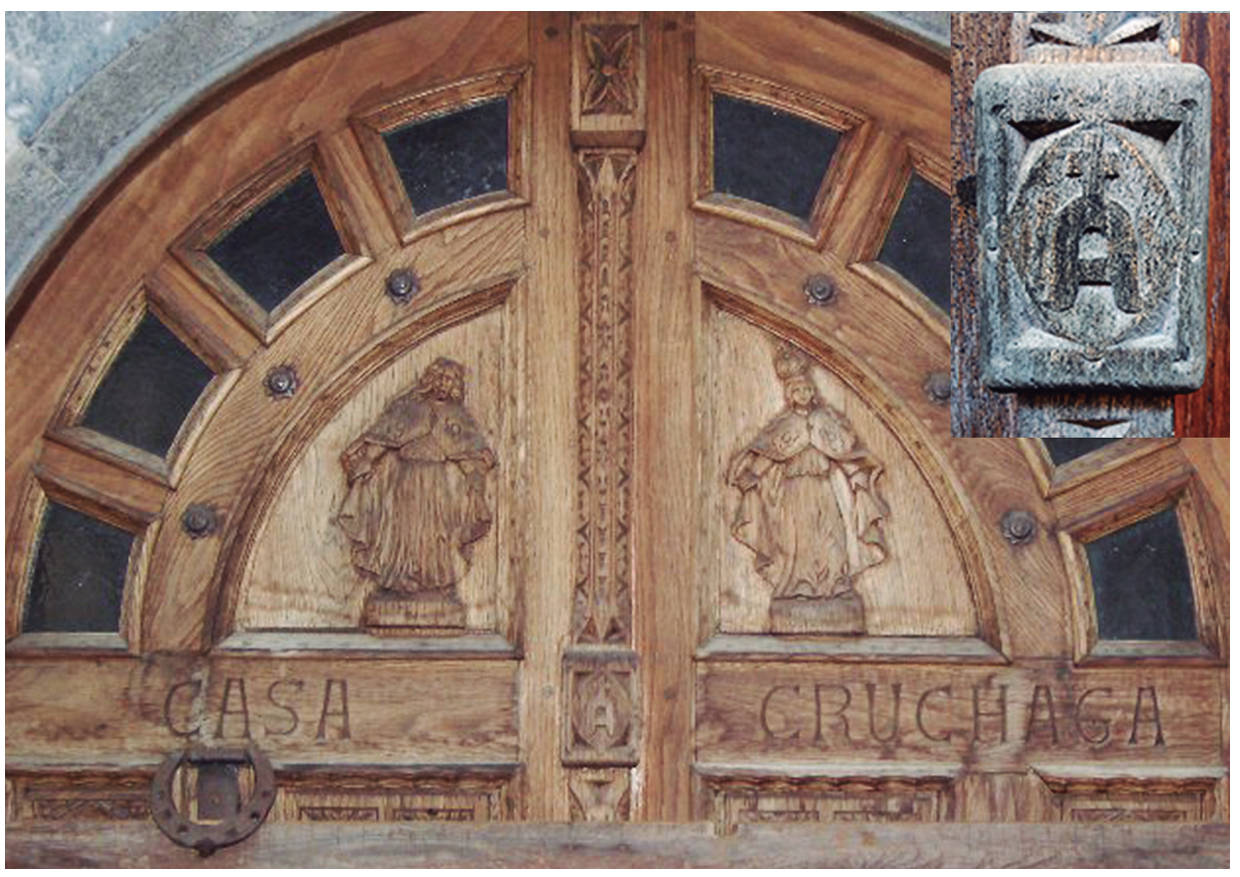

Figs. 8-9-10. Marcas de propiedad en las casas Krutxaga (Uztárroz), Ezker (Garde) y Diego (Vidángoz). / Property marks on the houses Krutxaga (Uztárroz), Ezker (Garde) and Diego (Vidángoz). Fuente: Equipo de campo.
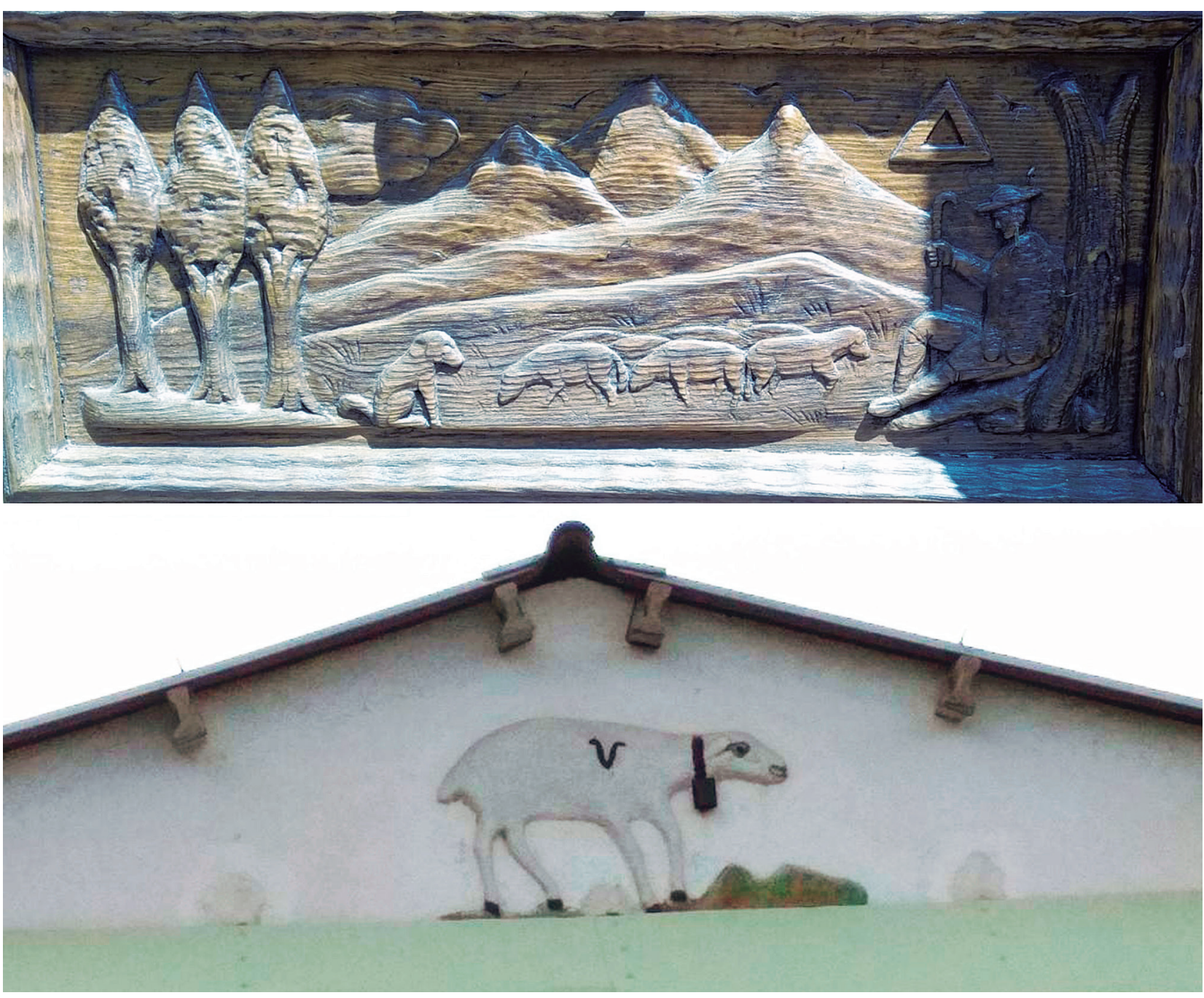
Este tipo de representaciones de marcas de casa en las puertas o muretes cobraban especial interés en las cabañas o corrales que los pastores roncaleses tenían en el desierto de las ribereñas Bardenas. Al impregnar con pez o hierro tal señal en sus entradas no sólo refrendaban su derecho de usufructo, sino que se mostraban como símbolos de protección para con sus moradores invernales (Mateo y Orduna, 2017: 160) [Fig. 11]

Este tipo de expresiones plásticas del ideograma coparticipan con otros elementos de diferente índole en la representación de la institución de la casa pirenaica como sujeto activo y diferenciado en la comunidad. Por ello, en el valle roncalés, no es que fuera mal visto, sino que se ejercía mucha persecución a cualquier intento de traseñalar a las reses. Este hecho se daba cuando se intentaban robar cabezas de ganado en otros rebaños o perjudicar a pastores contrarios en alguna disputa personal. Consistía en modificar la marca original para que pareciera como suya propia del cuatrero la cabeza de ganado robada.
Con el fin de evitarlo, sobre la pez se podía imprimir otra marca o esquilar al semoviente. Sin embargo, con la combinación de otras señales permanentes esto se convertía en algo más difícil de lograr. De ahí se derivaron las viejas marcas de hierro -fuegos- en los cuerpos, cuernos o frentes según el tipo de cabaña ganadera que fuese. A ello se unió el sistema de cortes personales -oxkëak, oxkak u oxketak en roncalés- que se hacían en las orejas del ganado ovino. Estas últimas eran permanentes y de más difícil mutación intencionada. Un dicho roncalés ya advertía que «oveja con la oreja cortada, oveja robada» (literalmente ardi zarrari gentan zau bëarria).

Sin embargo, a finales del siglo XX, auspiciado por la Administración Foral, muchas de estas marcas han ido desapareciendo, siendo sustituidas por los crotales como única señal de identificación del ganado. En el caso del ganado ovino, se trata ya de un marcaje vinculado a un censo veterinario y fiscal fundamentado principalmente en pendientes de plástico secuenciados. En ellos se registra mediante un código alfanumérico la

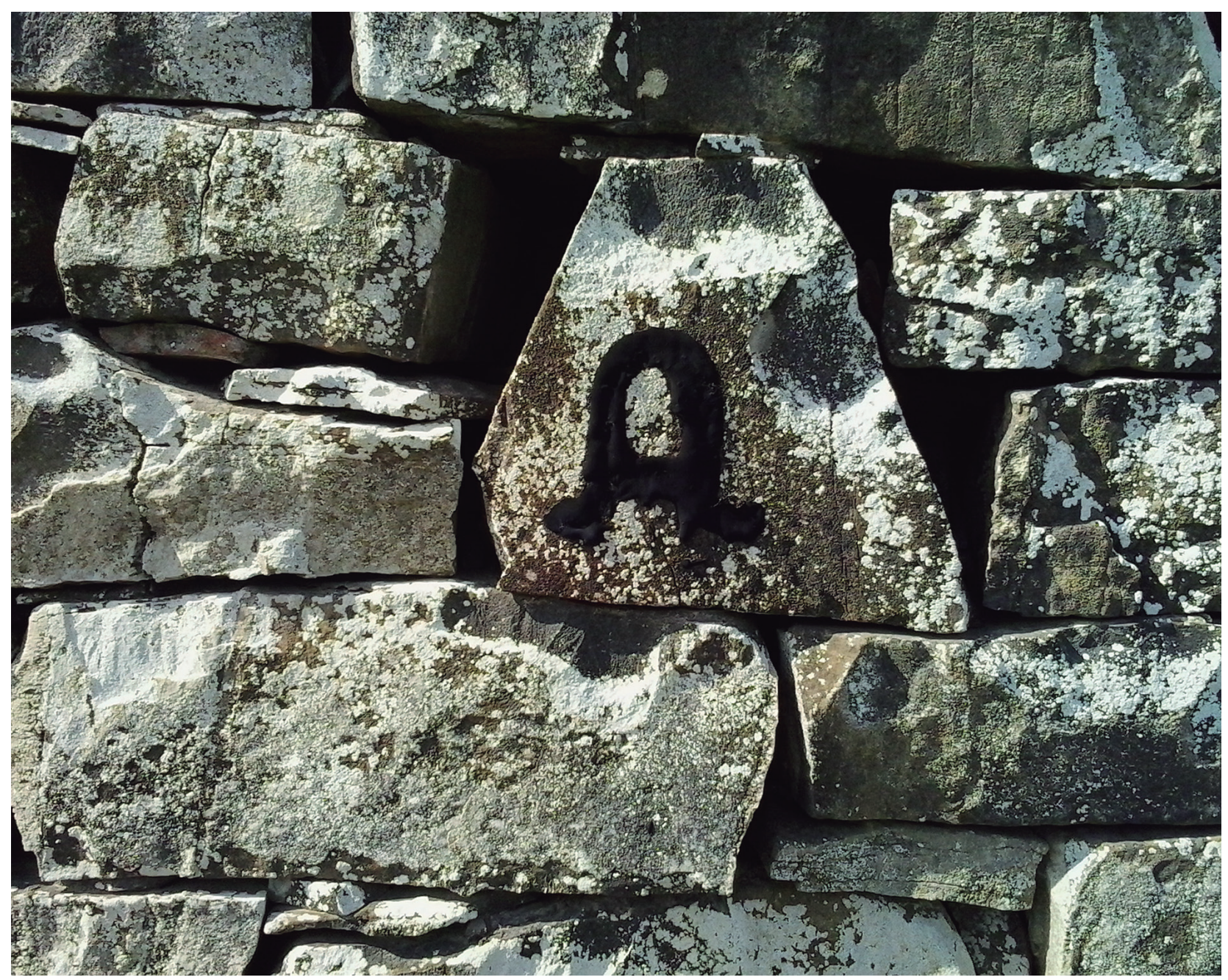

Fig. 11. Marca de Casa Arguedas (Vidángoz) en un muro de bordal. / Mark of Casa Arguedas (Vidángoz) on a bordal wall. Fuente: Equipo de campo. 
identidad de cada cabeza y su ubicación en la explotación concreta a la que pertenece. Su finalidad es distinta a la de las marcas tradicionales y ya no cumplen entre los vecinos la función de identificar con respecto a una casa y dueño. Junto a ello, todo el contenido inmaterial de su significado se ha desvanecido dejando protagonismo al registro de trazabilidad que ese animal tiene hasta su uso final (Barandiarán et al., 2000: 391394) [Fig. 12].

\section{RESULTADOS Y DISCUSIÓN}

\subsection{La marca de pez}

La marca más usada en el valle era la efectuada con un tampón diseñado mediante un ideograma propio de la casa. Éste se ejecuta en un material resistente que se impregna de pez caliente. Tal resina natural se estampa a las reses tras el esquileo, en el lomo o los costados del animal (Pallaruelo, 1988: 106; Orduna, 2014; Vacas, 2019: 23). Los utensilios marcadores solían ser en un principio de madera, con objeto de ser más prácticos y no quemar al ganado en el cuero cabelludo. Sin embargo, ya desde el siglo XX los que están extendidos son de hierro (Violant i Simorra, 1997: 410). Éstos lo único que conservan de madera es el mango constituido por un taco pulido, circular donde se incrustaba el tubo manejador del artilugio acabado en punta. Este mango, de en torno a $50 \mathrm{~cm}$ de largura, permite al pastor no dañarse con el calor que trasmite la pez caliente al metal. La resina oscura se pone a calentar y derretir en un caldero al fuego. Cuando está

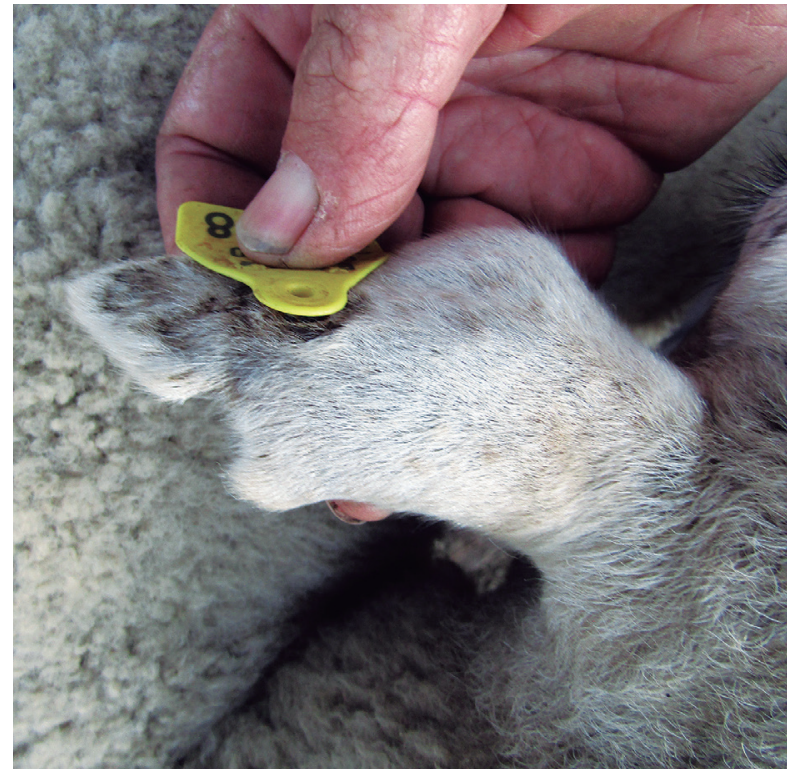

Fig. 12. Crotal en la oreja de una oveja de Casa Txurrust (Uztárroz). / Ear tag on the ear of a sheep from Casa Txurrust (Uztárroz). Fuente: Equipo de campo.

semilíquida se introduce la punta con el ideograma del marcador sumergiéndola levemente. Tras ello se van impregnado los lomos de las ovejas esquiladas. Tal acción se ejecuta varios días después de esquilar para que esta fibra natural se refuerce y la piel del animal se haya recuperado del rigor ejercido en el proceso de corte (Pallaruelo, 1988: 107) [Figs. 13, 14 y 15].

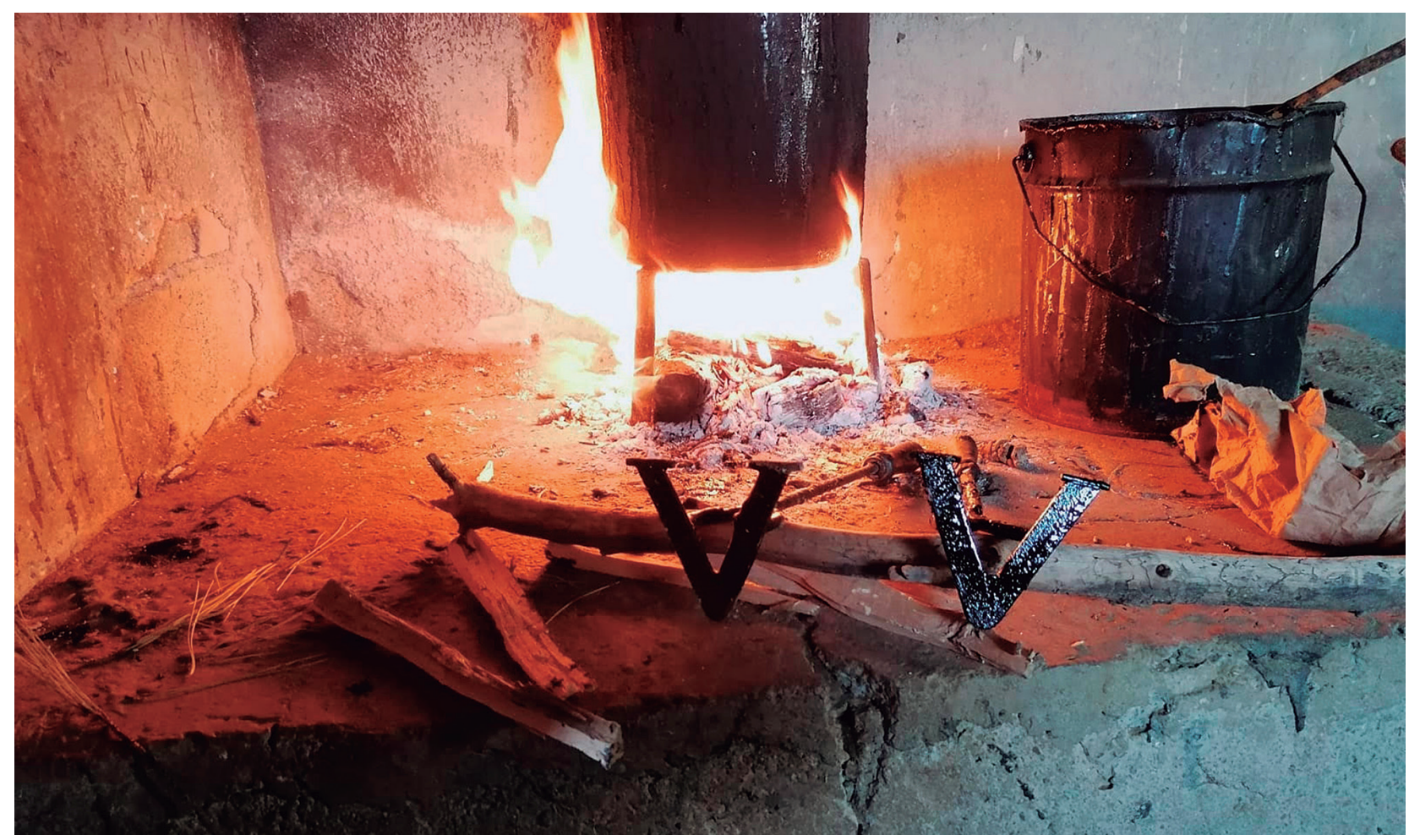




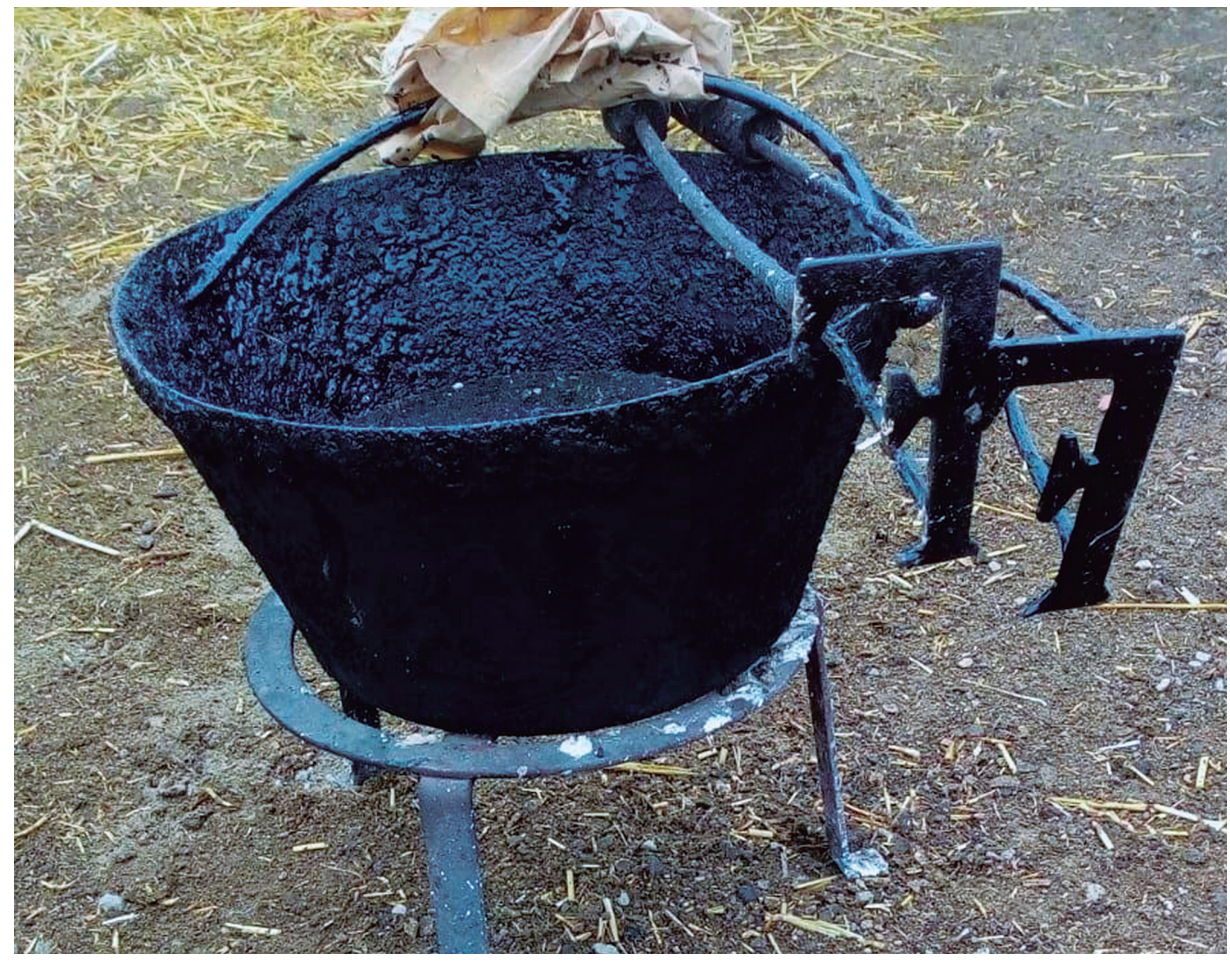

Figs. 13-14-15. Proceso de marcado en lana con pez caliente. / Process of marking wool with hot tar. Fuente: Equipo de campo.

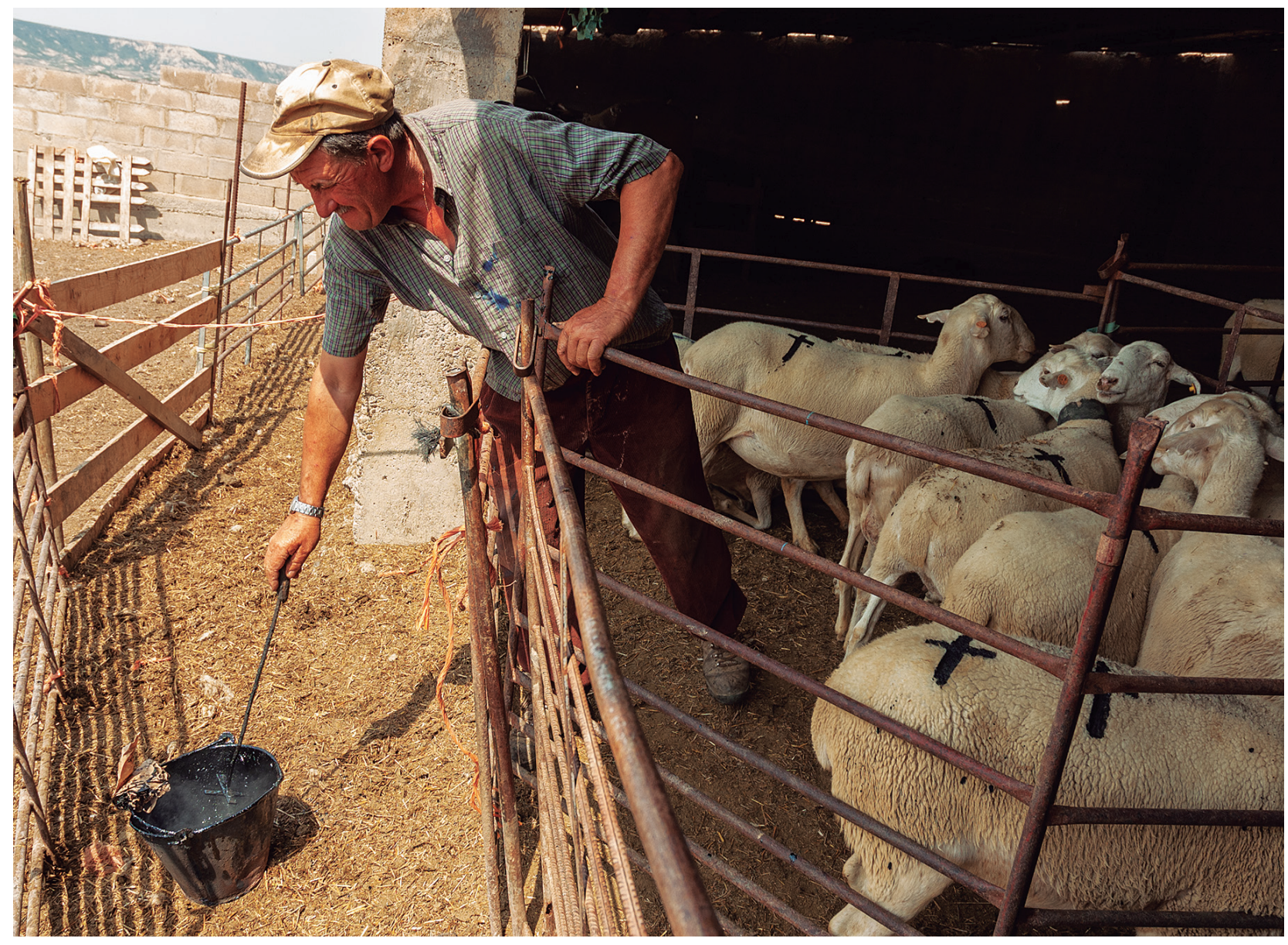


Desde los años 70 del siglo XX, se tiende a emplear en vez de pez pura una mezcla de ésta con tinturas artificiales o simplemente pintura líquida. En Uztárroz una familia ganadera se desplazaba hasta el pueblo navarro fronterizo de Luzaide - Valcarlos para comprar estas tinturas en las ventas situadas allí. Esto se debe a que ahí la importan desde Francia y su precio es mucho más competitivo que la producida al sur del Pirineo. Este cambio de la pez a la pintura se ha dado también debido a la mayor dificultad de encontrar ese producto antiguo. Por otro lado, su sustitución propicia dejar menos dañada la lana en esa zona al ser esquilada y vendida (Pallaruelo, 1988 107). En definitiva, resulta más barato, práctico y accesible. De hecho, hay quienes ya han ido abandonado incluso la costumbre de marcar y, por convertirse en ganado semiestabulado, han optado por emplear sólo los obligados crotales que pone la Administración unidos a chips insertos en los estómagos del animal [Fig. 16]

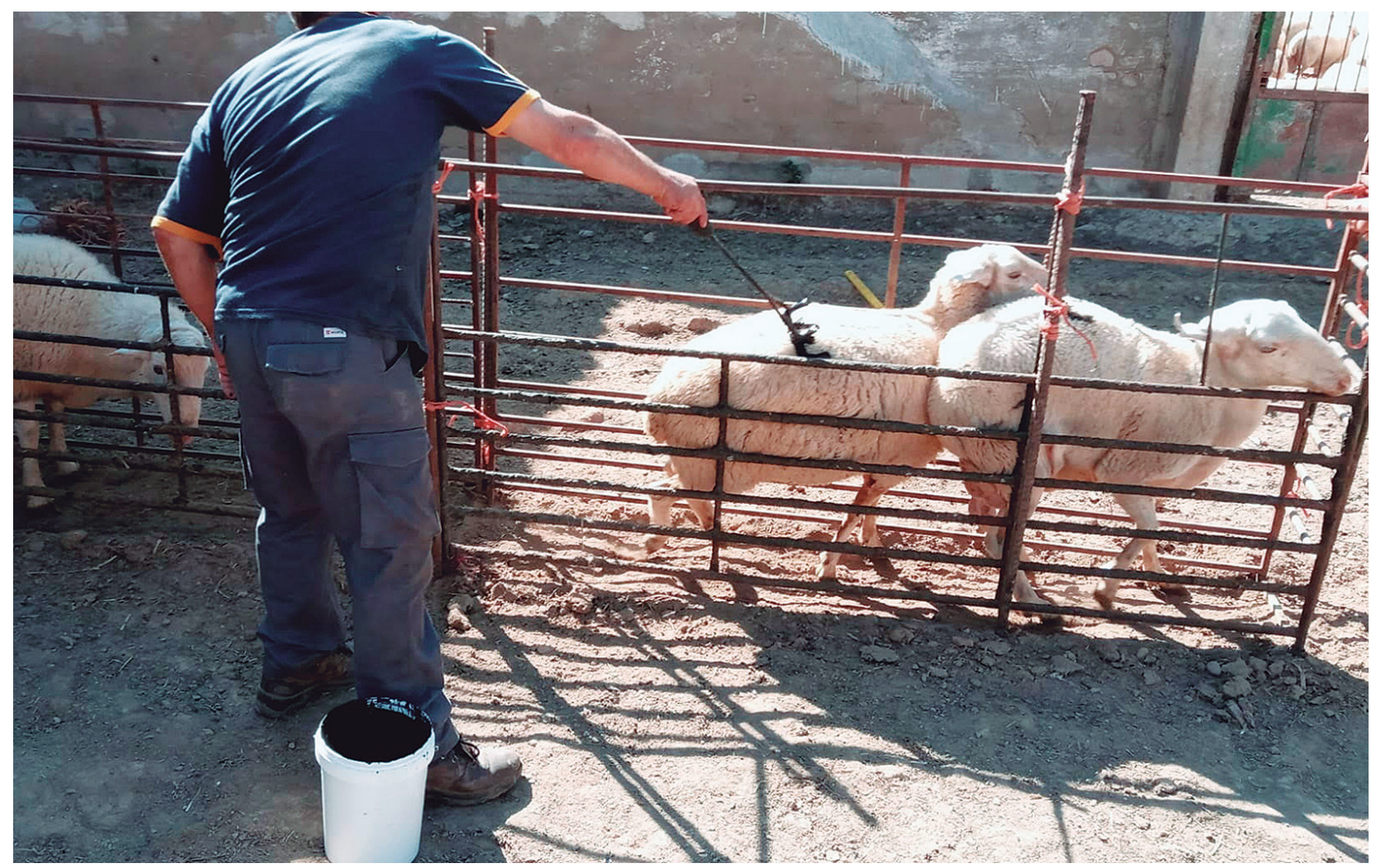

Fig. 16. Marcado de ovejas con tinte artificial sustituto de la pez tradicional. / Marking sheep with artificial dye substitute for traditional tar. Fuente: Equipo de campo.

En un entorno trashumante y de ganadería extensiva como el del Pirineo occidental, estas marcas tienen un valor identificativo no sólo a nivel de valle sino supra comarcal. Tales señales permiten separar los rebaños o cabezas de éstos si se juntan con otros pastores del territorio navarro de la cordillera o del otro lado de la muga con Aragón o Francia. Así mismo, poseen las mismas finalidades en la Ribera del Ebro donde pasan la invernada o durante el tránsito de las cañadas que los llevan de norte a sur y viceversa. Como señala Vacas (2019: 162), ahí donde estén «es el sello colectivo del rebaño, asegurando la identificación individual». La marca es siempre heredada por el nuevo amo y así nunca se desvincula de la casa a no ser que se decida cambiar por éste o que el ganado en su conjunto fuese vendido a otra casa con la marca incluida. Esta señal era igual en su ideograma tanto en su versión de pez como de fierro-hierro- [Figs. 17 y 18]

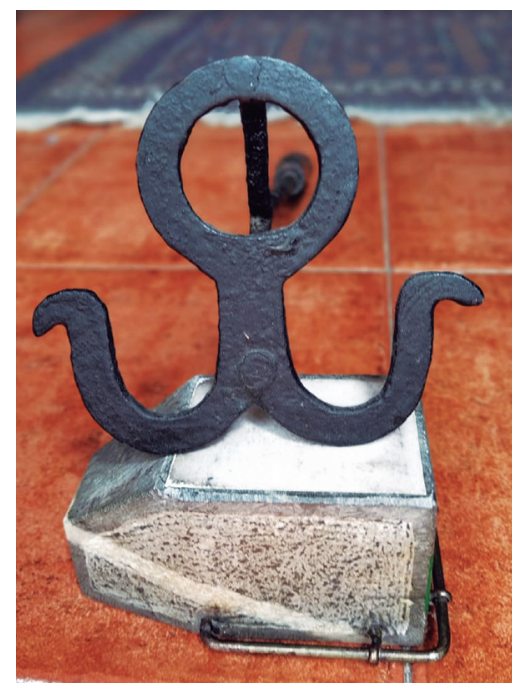

Fig. 17. Marca de pez de la Casa Mainate (Garde). Distintivo individuo de la figura jurídica en la colectividad. / Tar mark of the Casa Mainate (Garde). Distinctive individual of the legal figure in the collective. Fuente: Equipo de campo. 
Modelo de gráficos en el diseño de marcas

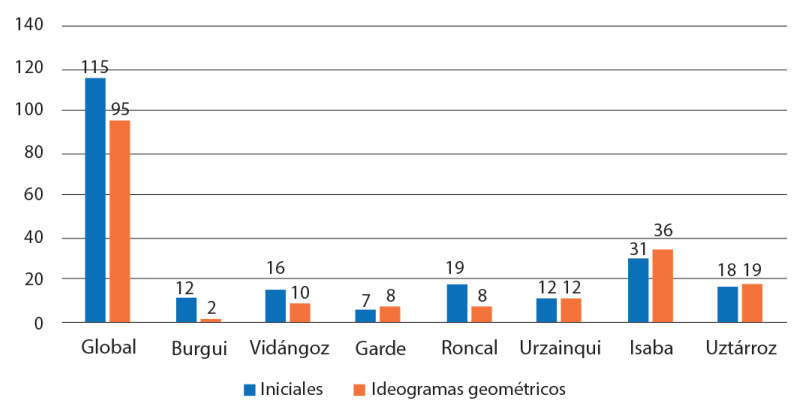

Fig. 18. Incidencia de los modelos gráficos en las marcas de pez y hierro. / Incidence of graphic models in pitch and iron brands. Fuente: Elaboración propia.

\subsection{Los hierros de fuego}

Sánchez Belda (1981: 31) asimila a este proceso de marcado al fuego con otras "marcas cruentas en las ovejas del ganado común". En cualquier caso, hay que señalar que el marcado a fuego ha estado muy presente en la tradición ganadera europea y, por ende, pirenaica (Sánchez Belda, 1981: 99). El herradero de bovinos y equinos sigue manteniéndose muy activo hoy en día en la península. Sin embargo, como se verá, en el Valle de Roncal se ha ido abandonando incluso en el ganado mayor. El motivo es que su desarrollo supone diferentes inconvenientes y peligros, así como un costoso tiempo de trabajo muy engorroso que en otras regiones, por el contrario, se entienden como momentos festivos y de reunión colectiva o familiar al menos (Sánchez Belda, 1981: 102-103).

Este tipo de señalamiento se efectúa con tampones de hierro -yerro- puestos al rojo vivo en el fuego que dan lugar a una marca indeleble, asegurando de forma más efectiva el dominio y propiedad sobre el semovien- te (Mesa, 2004: 42; Landais, 2000: 350). En el contexto hispano, según Vacas (2019: 164), «las primeras disposiciones sobre el marcado a fuego se encuentran en el Fuero Juzgo. Estas marcas se ponían en la base de los cuernos, en los cascos de las pezuñas o en el morro del animal, lugares que era imposible el eliminarlas sin sacrificar la res». En Roncal las leyes se basan en el Derecho Foral Navarro y el derecho consuetudinario recogido en las Ordenanzas del Valle. Sin embargo, en esta región, el empleo de la marca de fuego también ha tenido tradiciones y costumbres muy similares a las ya señaladas fuera de las mugas de la comarca.

Con este tipo de signos permanentes se logra impedir establecer cambios o confusiones en la identidad y posesión del animal evitando todo tipo de contramarca ilícita (Mesa, 2004: 44-45). Es decir, se impide que cualquier cuatrero pueda traseñalar a la oveja o cabra. En el caso de las vacas y ganado caballar es una práctica más que habitual ya que no se emplea la pez. Ahora bien, hay constancia de que en Uztárroz no se ejercía este marcaje a fuego entre los bóvidos, mientras que en el resto de las villas del valle sí.

En el caso de la cabaña ovina, desde hace cincuenta años, ya no se desarrolla el herraje a hierro caliente. Sin embargo, con anterioridad, sí se marcaban con hierro rusiente los cuernos de las vacas, carneros y cabras. Se hacía en la cepa o parte baja de su nacimiento donde el asta está 'viva'. En el caso de la villa de Vidángoz se disponía esta marca también sobre la mandíbula superior de las ovejas y en Uztárroz en su frente, lugar éste escogido por la mayoría de los pastores de las otras cinco villas roncalesas [Fig. 19].

Una variante del marcado a fuego fue el corrosivo en el que se empleaban los instrumentos del anterior, u otros exprofeso, para impregnar con líquido cáustico (Sánchez Belda, 1981: 104-105). Sin embargo, Este

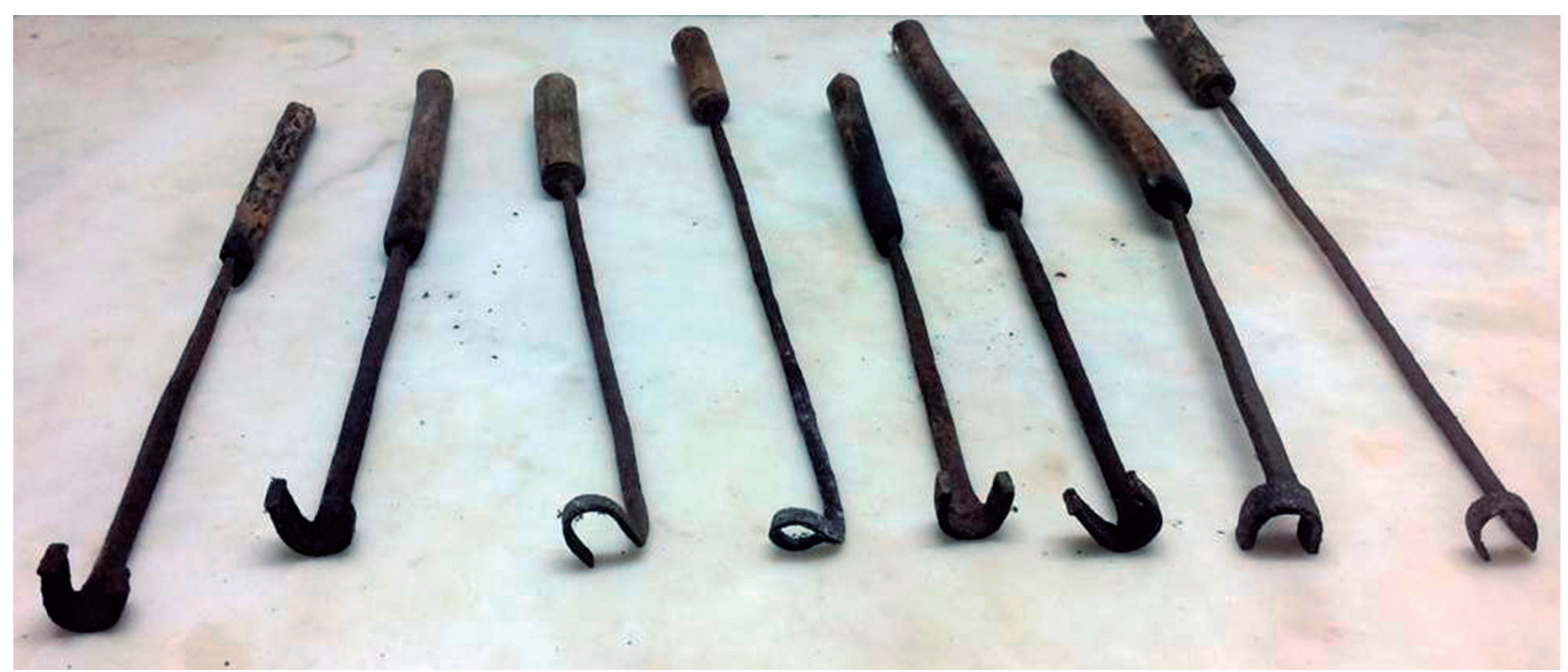

Fig. 19. Hierros de marcar las ovejas y enseres de la casa Txurrust (Uztárroz). / Sheep branding irons and tools of the Casa Txurrust (Uztárroz). Fuente: Equipo de campo. 
modelo de técnica no se ha documentado en el valle roncalés a estudio.

\subsection{Las oxkak o señales en oreja}

Como bien señala Pallaruelo (1988: 99), los pastores del Pirineo distinguen entre marcar y señalar. Con la primera expresión se refieren a la ya mencionada marca de pez. Con la segunda, a la identificación que hacen en el ganado joven que queda para casa y no se va a vender. Se trata de efectuar diferentes combinaciones de muescas en las aurículas. Práctica que es no sólo extensible a las zonas propias del Pirineo sino también del ámbito peninsular y continental vasco (Leizaola, 1977, 1978 y 1991: 22; Blot, 1984; Cavaillès, 2003; Dabadie y Etchezaharreta, 2017).

La señal de la oreja consiste en efectuar un corte recto, diente de sierra, un agujero u otra figura lineal. Esta rasgadura permite acreditar la propiedad y distinguirla de las de otros rebaños u otros propietarios de forma permanente (Vacas, 2019: 162). Tal sección se efectuaba con tijeras (más bastas), navajas (más pericia) o tenazas especiales (Violant i Simorra, 1997: 412; Pallaruelo, 1988: 99). En el valle roncalés al emplearse las navajas se procura que su filo y punta estén algo romo por desgaste para controlar la operación al doblar el pliegue de la carne de la oreja y proceder al corte. Las tijeras por su lado ayudan a hacer triángulos de ángulos más rectos.
Cada ganadero diseña su marca particular combinando las diferentes variedades de cortes. Esta marca no trasciende el espacio laboral del manejo pecuario como sí hacen las anteriores (Barandiarán et al., 2000: 380-381). En el Pirineo se daban seis modelos de corte diferentes que se interrelacionaban dando lugar a un verdadero código complejo de pertenencias (Pallaruelo, 1988: 99) [Fig. 20]

La disposición de las señales en las orejas puede ser tanto en la izquierda como en la derecha. Los más puristas dedican un mayor esfuerzo y tiempo en marcar ambos pabellones. Este tipo de señales se denominan en roncalés, tanto en el dialecto vasco local como en castellano: uesca, oxketa, oxka u oxke. Aunque, según su posición en la oreja del animal y el tipo de corte efectuado en ella, poseían un nombre diferente. Básicamente los cortes son de tres tipos: circulares completos, semicírculos y ángulos -de diferentes grados o secciones transversales en la punta del pabellón auricular-. En Vidángoz como oxketa se denomina en concreto a la muesca efectuada en la punta en ángulo agudo. Por el contrario, como punto o agujero se determina a un orificio abierto en esa extremidad sin despuntar. Ramo se llama a un corte en ángulo recto siendo adelante o atrás según la posición en el borde de la oreja. El espunte consiste en el corte en la punta y es izquierdo o derecho. Por su lado, la osca atrás u osca adelante es la muesca creada en el lateral posterior o anterior del pabellón [Figs. 21 y 22].

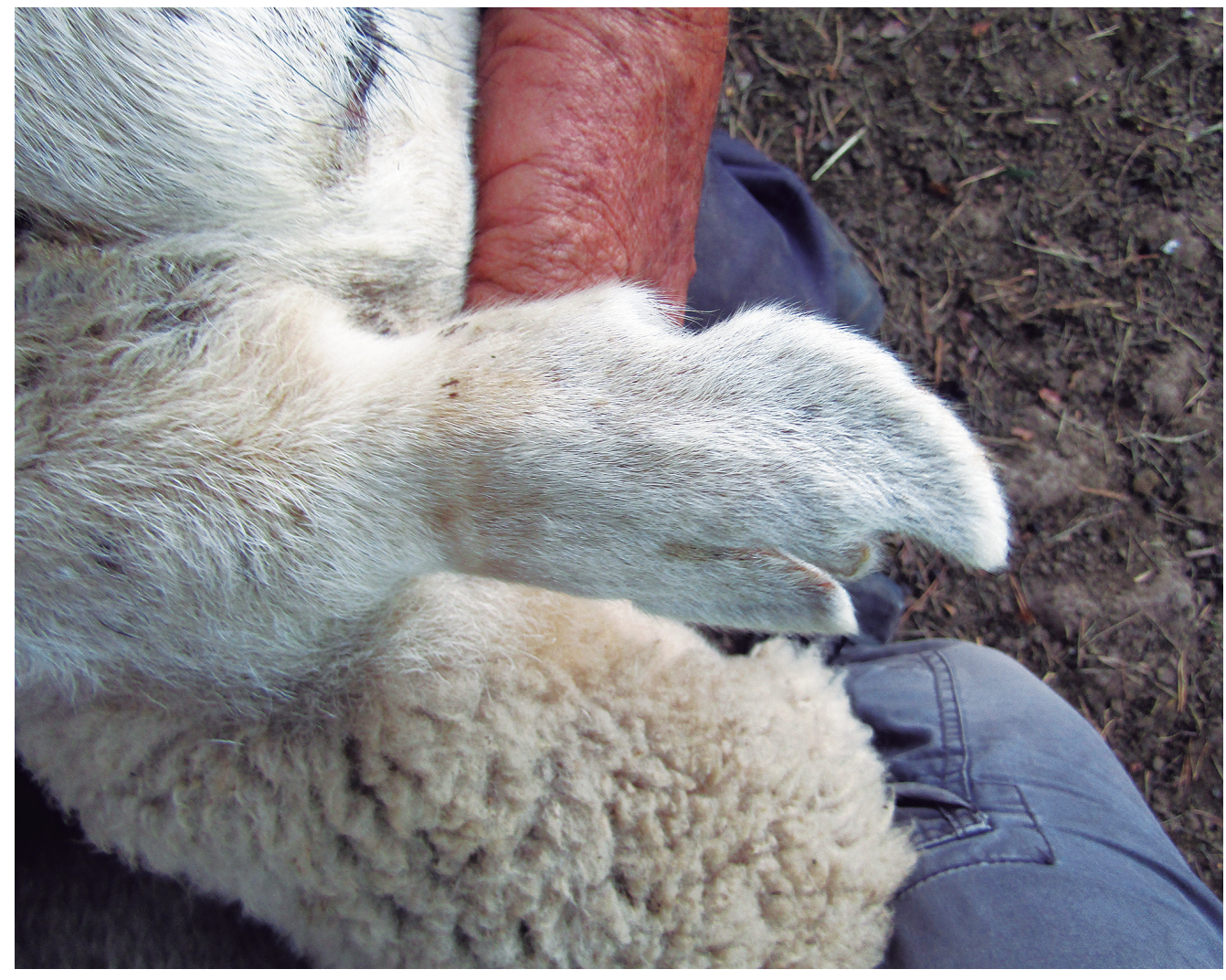

Fig. 20. Oxkak en las ovejas del ganado de la casa Txurrust (Uztárroz) / Oxkak in the sheep of the cattle from Casa Txurrust (Uztárroz). Fuente: Equipo de campo. 

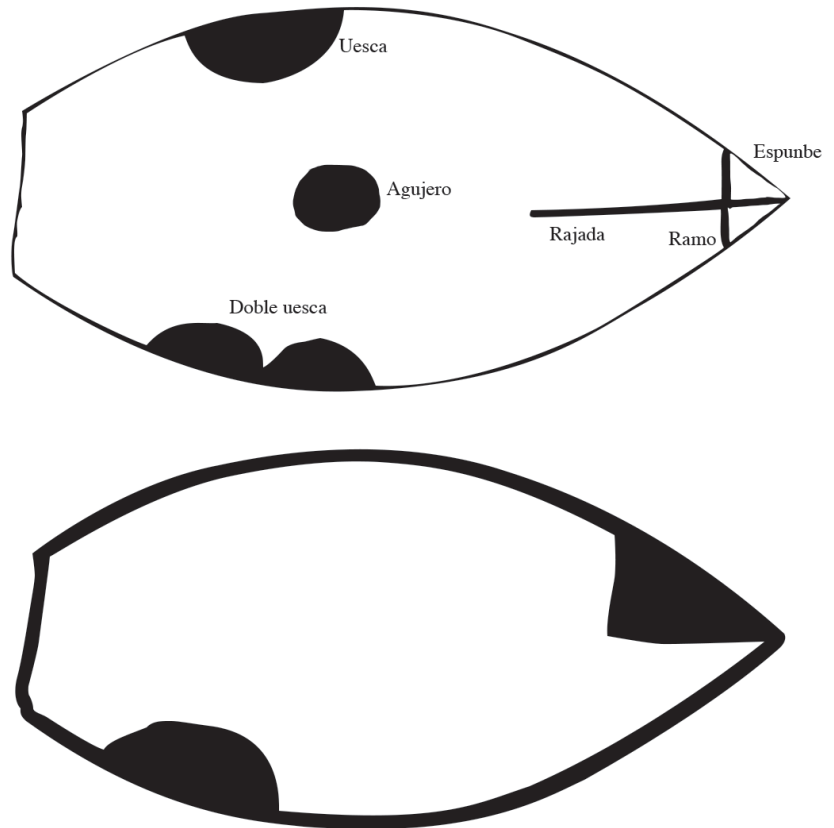

Figs. 21-22. Muescas generales del valle y ejemplo de Casa Txurrust (Uztárroz). / General notches of the valley and example of Casa Txurrust (Uztárroz). Fuente: Elaboración propia.

En el resto de los pueblos las denominaciones son similares con mínimas variaciones: muesca, horqueta, despuntada, hosca o de sistemas de ejecución en forma y posición (Barandiarán et al., 2000: 383). Así, en Uztárroz el agujero se puede situar en el centro del pabellón. En el mismo lugar, al corte limpio y recto sin ángulo se denomina rajada; y la uesca u osca lateral podía ser simple o doble con dos muescas consecutivas. Por ejemplo, la Casa Txurrust emplea un espunte derecho en ángulo recto una uesca simple izquierda delantera -cerca de la punta- y otra doble izquierda trasera. Por otro lado, entre las denominaciones empleadas para designar los diferentes estilos de cortes se ven claros indicativos que apuntan a un origen romance navarroaragonés, en gran medida, vasconizado en el contexto dialectal euskérico de la zona. Nombres semejantes con raíces etimológicas iguales o parecidas se recogen en los también pirenaicos y cercanos valles de Ansó, Hecho, Broto o Bielsa en Huesca (Sardaña y Reiné, 2009: 43-45; Pallaruelo, 1988: 99). Con denominaciones diferentes las registró Leizaola (1991: 29) en Aitzgorri y Aralar (Gipuzkoa): urkilloa, mirubuztan, akatza... Aunque con el mismo fin de marcado y protección contra acciones de traseñalado por parte de ladrones o vecinos enfrentados. Por otro lado, Landais (2000: 352354), nos remite a prácticas similares con técnicas muy parecidas que han sido referenciadas en espacios tan distantes como Noruega, Irán o Madagascar.

Estas marcas son perennes a no ser que se corte de raíz la extremidad del apéndice auditivo exterior. Además, las combinaciones de dibujos en sus cortes se vuelven múltiples por lo que imposibilitan mucho la capacidad de traseñalar en caso de robo o carneramiento -prendamiento- indebido. Tal versatilidad de marcaje hizo que esta técnica se extendiera por todas las regiones ganaderas del estado existiendo referencias de ello desde el Pirineo hasta las Islas Canarias (Suárez, 2019: 88-95). En las Encartaciones de Bizkaia a las becerras también se les efectúan cortes a modo de marcos en las orejas: «un total de seis, vista la vaca desde atrás: horcón u horconillo, abierta media oreja, abierta oreja entera, escuadra, sacabocado, media oreja» (Cordón, 1987), registrándose hasta un total de 22 combinaciones. En Roncal por el contrario no se efectúa este tipo de marcado en pabellones auditivos ni en el ganado vacuno, ni en el equino ni el caprino.

En relación con las cabras, en Canarias por su parte se da el caso curioso de Tenerife. En esta isla, ya en 1524, recién iniciada su conquista, se registraban en un protocolo de escribanía todos y cada uno de los tipos de corte y sus propietarios. Así mismo, como ocurre con cada villa roncalesa en el caso de las ovejas, una a una las islas del archipiélago tienen sus propios registros y variedades de muescas con sus nombres particulares (Lorenzo, 2002:131-164; Mesa, 2004: 3842; Pérez, 2009: 37-39 y 106-108). Así, en Lanzarote, «las señales se pueden hacer en una oreja, repetir la misma señal en las dos orejas, varias marcas en una oreja, combinar dos marcas en una oreja, repetir esta combinación en las dos orejas o realizar en cada oreja señales distintas» (Hernández y Rodríguez, 2000: 65). Este sistema de combinaciones es sumamente parecido al empleado por el conjunto de pastores roncaleses.

En algunos lugares como Tenerife se desarrolla un sistema denominado 'media marca'. Éste consiste en infringir a los animales cortes en las orejas propios de dos partes contratantes que hayan hecho un acuerdo comercial con ese semoviente como objeto el mismo. Destinan para ello una oreja para cada una de las partes contratantes. En otras ocasiones incluso crean unificando sus diseños una nueva 'marca entera' común a ambos en relación con ese hecho contractual. Este tipo de señales han sido remitidas a los registros de los cabildos para que queden referenciadas (Mesa, 2004: 43-44). Tal tipo de marcajes no han sido observados en Roncal como parte de sus códigos tradicionales de identificación del ganado. Tampoco se da la práctica de las contramarcas o contraseñales que consiste en efectuar nuevos cortes en animales ya señalados debido a un cambio de propiedad, trueques, donaciones (Palombo, 1998: 330-331 y 350-351). Por contra, si un pastor agrega sus ovejas a las del mayoral para pastorearlas conjuntamente, comparte con éste la marca de pez, pero mantiene las suyas propias en las uescas de las orejas registrándolas por separado en los libros del Ayuntamiento.

Así mismo, a diferencia de en otros territorios fronterizos, en las facerías del Pirineo Roncales mugante con Baretous (Bearn) no se efectuaron procesos de marcado de ganado, ni con muescas ni con hierro, como sí se 
producen en los pastos de uso común en Sorogain entre Baigorri (Baja Navarra) y Erro (Alta Navarra) (Aragón Ruano, 1918). Por otro lado, en el valle de Roncal no se dieron casos de formas de 'contrato o sociedad a media ganancia', que tan presentes fueron en Gipuzkoa desde el siglo XVI al XIX con participación incluso de ganados navarros en sus seles o saroiak (Aragón Ruano, 2015). Es lo que en la vecina Zuberoa serían las partes -txotx- en que dividen varios propietarios un único kaiolar. En esos casos, todas las cabezas de ganado llevan diferentes códigos de marcas de color en pintura que los relacionan tanto con el conjunto del majadal como con su propio dueño particular (Cunchinabe et al., 2013: 77). Un sistema parecido se sigue en el paralelo bearnés - cujala- de estas cabañas con majada en los puertos (Le Couédic, 2010: 334; Casaurang, 2002).

Ahora bien, hay que señalar que por la complejidad de su ejecución y el trabajo y coste en tiempo que supone, conforme se fue implementando la obligatoriedad del empleo de crotales esta técnica ha ido cayendo poco a poco en desuso. En el valle quien la sigue manteniendo son los trashumantes. Al ser su sistema de explotación extensivo y de largos recorridos las ovejas suelen enredarse en matorrales o cercas de alambre lo que en ocasiones engancha a los pendientes plásticos desprendiéndose de las orejas que se desgarran. Por ello, este tipo de pastoreo prefiere seguir manteniendo el empleo de las ozketak o uescas como medio certero de identificación como propia de cada cabeza de ganado.

Es obvio que tanto los crotales como las pinturas de aerosol han ido sustituyendo a estas complejas muescas y, por ende, a la pez y el hierro en casos concretos. Se trata de aquellas explotaciones de ganaderías no extensivas ni trashumantes y estabuladas de ovejas latxas sitas de forma permanente durante todo el año en el Valle. Básicamente se han sustituido y siguen patrones de uso de color en pintura a como se hace en la vertiente mugante del Pirineo francés ya de forma mayoritaria desde hace treinta años. Así, la ficha del Inventario de Patrimonio Inmaterial francés dedicada a la ganadería trashumante se señala que en el Pirineo, "pour préparer la montée en estive, le propriétaire du troupeau marque la bête à la peinture (initiales ou symbole, dits alors «pégadé»)" (Campello y Péquignot, 2021: 41).

En cualquier caso, como señala Anne Aragon (2018: 59), es un sistema que desarrolla "des marques de forme, localisation et couleur différentes permettent de déterminer à qui les animaux appartiennent sur l'estive [...]. Cela permet d'identifier de loin les brebis lors de l'observation aux jumelles ou lorsqu'un cadavre est retrouvé. Elles sont réalisées à l'aide de bombes spray de couleur, de tampons avec une marque spécifique (lettre, étoile ...) ou encore d'un mélange réalisé avec un colorant et appliqué au pinceau afin que la marque tienne tout l'été". 1

\subsection{Significación ideográfica: ideogramas y discurso etnocultural}

Como se ha señalado, el diseño de la marca en pez o en fuego es idéntico y sólo variaba el tamaño del tampón en el caso del ganado ovino. En estos casos el sello destinado a la pez es mayor que el empleado en grabar a hierro rusiente ya que en este segundo modo se señala en partes más pequeñas como los cuernos o frente del animal. En el marcaje de las yeguadas y manadas de vacas o vaquerías la marca de hierro es mayor al disponerse en muslos u otras partes de unos semovientes ya de por sí de gran volumen corporal. Se tiende a elegir posiciones traseras sobre el rabo, en el anca o riñonada. Sí es cierto que, en el caso de los bóvidos, cuando lo que se marca son los cuernos, el utensilio reduce su tamaño como en el caso de ovejas y cabras.

El diseño de las marcas nos señala el carácter cultural y la significación que tiene el símbolo o ideograma en el seno de la comunidad roncalesa. En este valle la tendencia que se sigue es similar al resto del Pirineo circundante. Así, por ejemplo, en líneas generales, el estudio comparativo de la tipología del lenguaje ideográfico de esta comarca navarra con el valle oscense de Broto revela ciertas consonancias y parecidos. En ambos enclaves, se da una preponderancia de iniciales, letras o anagramas estilizados de nombre, apellidos, nombres de las casas o combinaciones de todos ellos (Sardaña y Reiné, 2009:45) [Figs. 23, 24 y 25].

Es verdad que, por ejemplo, en Aragón, en Broto, ese porcentaje es muy alto - $71 \%$ - y que en Roncal la paridad es casi al 50\%, como se expresa en el gráfico de la figura 6 y ya se observó en la figura 3. Es de destacar que en la villa de Burgui el dominio de las iniciales es absoluto, con 12 de éstas sobre 14 en total. Así mismo, en la localidad de Roncal resalta la alta presencia de signo alfabéticos dobles con respecto a lo que se observa en el resto de los pueblos del valle. En este caso se determina que el significado de ambas letras hace referencia al nombre y apellido o a los dos apellidos de los miembros de la casa ganadera [Figs. 26 y 27].

Por otro lado, se puede presuponer que muchos de los signos geométricos no correlacionados con iniciales de nombres y apellidos pueden corresponder a concepciones protectoras a modo de amuletos (Violant i Simorra, 1997: 410). Se trataría de ideogramas de diseño y factura más antiguos que los alfabéticos. Sin embargo, en la actualidad ningún informante hace re-

\footnotetext{
1 Sobre la normativa actualizada en 2015 del sistema de l'identification des animaux des espèces ovine et caprine, modificada del original de 2005, en Francia ver: https://www.legifrance.gouv.fr/loda/id/JORFTEXT000000633936/
} 


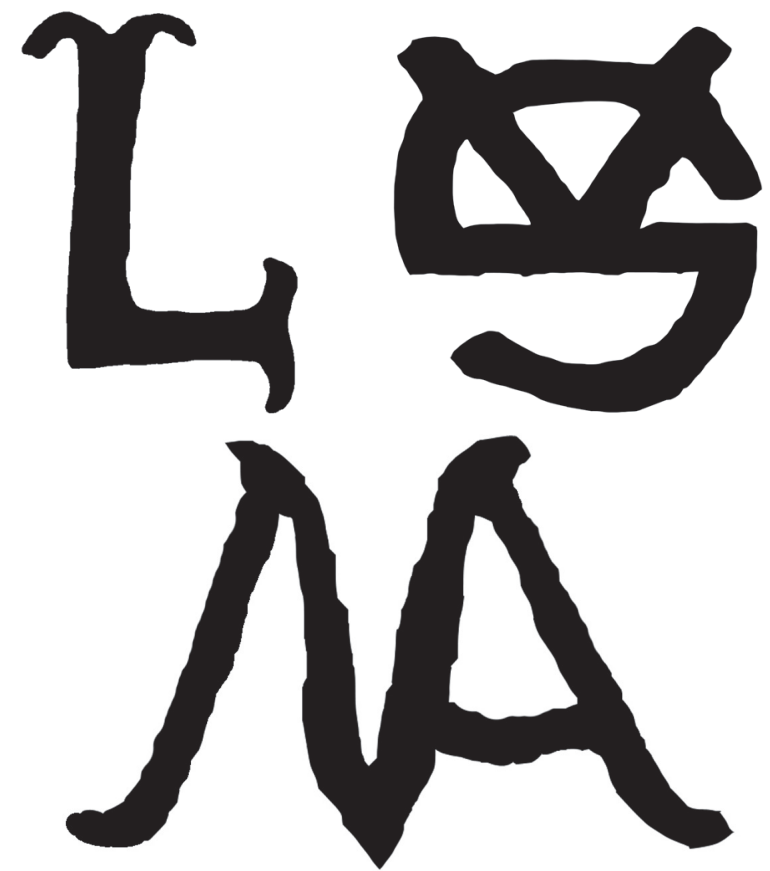

Figs. 23-24-25. Marcas de pez de las casas Monzón (Roncal), Biratx (Garde) y Mendigatxa (Vidángoz). / Pitch marks of the houses Monzón (Roncal), Biratx (Garde) and Mendigatxa (Vidángoz). Fuente: Elaboración propia.

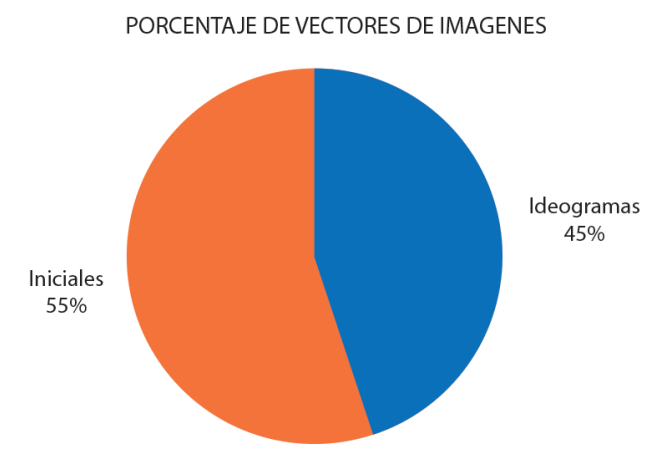

Fig. 26. Volumen porcentual en el valle en las dos tipologías de signos principales. / Percentage volume in the valley in the two main sign typologies. Fuente: Elaboración propia.

\section{PORCENTAJE DE MODALIDAD DE INICIAL}

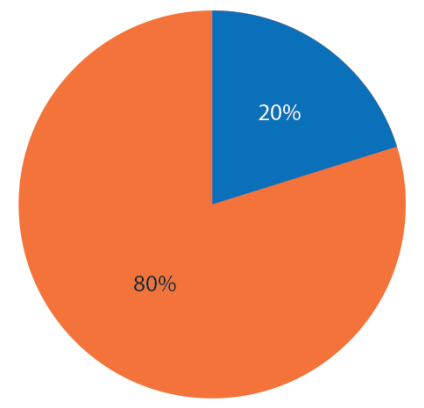

- Inicial única Inicial doble

Fig. 27. Volumen porcentual en las dos modalidades de iniciales a nivel de valle. / Percentage volume in the two types of initials at valley level. Fuente: Elaboración propia. ferencia a tal función inmaterial relativa a las creencias populares precristianas. Sí es cierto que las marcas más recientes en su creación responden predominantemente a iniciales de nombres propios, por lo que se han ido relegando esas otras antropomorfas, estilizadas, que constituyen anagramas de difícil interpretación, pero, en ocasiones, de gran belleza estética. En cualquier caso, en ellas siguen predominando diversos diseños elementales muy antiguos que se han perpetuado de generación en generación y de raíz arcaica: rayas, puntos, círculos, cruces diversas o más de tipo arabesco (Barandiarán et al., 2000: 386) [Figs. 28 y 29].

En el caso del pueblo de Uztárroz se observa una acusada presencia de signos vinculados a la figura de la cruz, griega o latina, agregados a otras figuras geométricas o letras. Esto podría tener un valor simbólico precristiano o religioso en algunos casos. Así, en la Casa Txurrust, tras la Guerra Civil, en el año 1940, hay constancia del cambio desde la marca antigua inicial de $U$ cuadrangular a una cruz [Fig. 30].

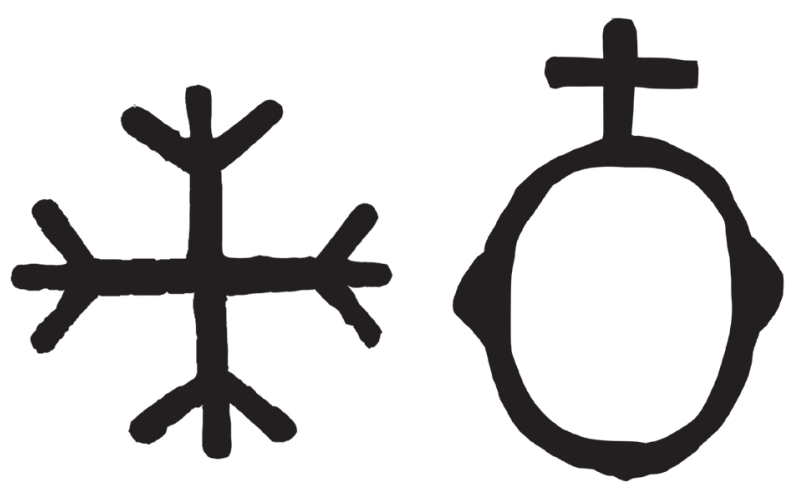

Figs. 28-29. Marcas de pez de las casas Urrutia (Burgui) y Zapatero (Urzainqui). / Pitch marks of the Urrutia (Burgui) and Zapatero (Urzainqui) houses. Fuente: Elaboración propia.

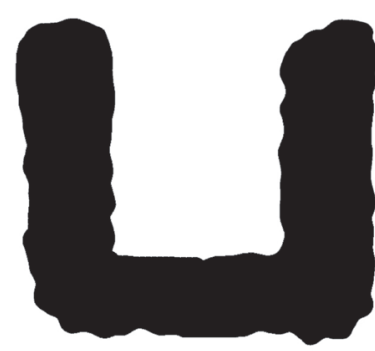

Fig. 30. Marca de pez primitiva de la Casa Txurrust (Uztárroz). / Primitive tar mark of the Casa Txurrust (Uztárroz). Fuente: Elaboración propia.
Ha de recordarse que la marca posee un valor más elevado que la mera disposición en propiedad del semoviente. Así, por ejemplo, a las ovejas martas, negras, se les marcaba de forma especial. En la actualidad se referencia que tal hecho se sujetaba a que el pelaje del animal impedía ver de forma alguna la señal de pez. Aunque no hay que olvidar que, en la cultura de la cordillera, y en otros lugares, se les dio un valor de animal protector. Se trataba de especímenes muy apreciados ya que se 
consideraba que servían de amuleto y a su vez de puntos referenciales para hacer el conteo del conjunto del rebaño a larga distancia. Esto se debía a que una oveja negra equivalía a otra cantidad de blancas en número. Por ello, se tenía especial deferencia para con estas ovejas singulares sufriendo menos marcajes o menor incidencia de sacrificios para carne, etc. (Vacas, 2019:64). Por su parte, Pallaruelo (1988: 107) ya referencia que a estos animales de pelaje oscuro se les marcaba en el Pirineo aragonés echándole ceniza a la pez antes de secarse para aclararla y así se dejara ver. Es el mismo sistema que se seguía en el valle navarro roncalés.

Por otra parte, quedaría para otro estudio la relación de estas marcas del ganado con las marcas que se realizaban a cada uno de los maderos que conformaban una almadía. Si bien por lo general las diferentes casas del valle de Roncal solían ser o ganaderas o maderistas, no son raros los casos en que una casa ganadera bajaba alguna almadía como una manera de diversificar su actividad y sus ingresos. Ahora bien, la tipología de las marcas realizadas en la madera es diferente por no realizarse habitualmente con fuego -yerro- sino con el propio estral, el hacha (Labeaga, 1992). De esta forma, se encuentra alguna similitud entre la marca del ganado de alguna casa y la marca que realizaban los de esa misma casa en los maderos de sus almadías. Por ejemplo, señálese cómo en Casa Pantxo de Vidángoz, la marca de las almadías era IIXI y la del ganado, cuando lo hubo, fue una $X$ [Fig. 31].

En ambas vertientes del Pirineo vasco, como apunta Landais (2000: 349), se puede señalar que como toda sociedad pastoral se ha marcado el ganado siguiendo las técnicas utilizadas de manera tradicional (marcado con fuego, incisión fuego, incisión de las orejas o una combinación de ambas), que aportaban no sólo un rango de propiedad al semoviente sino una correlación con su pervivencia patrimonial supra utilitaria. Entre el final del siglo XX y el inicio del presente se ha establecido una dialéctica que evalúa la pertinencia de su conservación o la continuidad en la deformación en los procesos de la transmisión vertical y horizontal de las marcas dentro de estas sociedades. Se ha establecido un patrón de pérdida sin fin de continuidad de gran parte del contenido y el significado del mensaje que transmite su ideografía. Es decir, estas marcas están en peligro de desaparecer o convertirse en un mero folklorismo alejado de la significación de su interpreta- ción como signo del pacto comunitario constitutivo del sistema pastoral que, en palabras de Landais, une a una comunidad humana con la animal y con un territorio. Aspecto simbólico éste que puede trasladarse también al modelo de marcaje forestal ya mencionado y que vincula a la casa con sus explotaciones madereras y otras propiedades anexas.

\section{CONCLUSIONES}

La Comisión FAO/OMS del Codex Alimentarius en su fase final de la negociación de un nuevo Código de Prácticas Higiénicas para la carne, entre otras muchas materias, determinó qué procedimientos son los adecuados para marcar al ganado en las explotaciones pecuarias. Entre estas técnicas apostó por el marcaje en frío, el tatuaje, a hierro ardiente, crotales, diferentes métodos de señales señal de radio frecuencia o a través de métodos de registro genético. Como se puede ver, de los métodos tradicionales sólo se mantiene el marcado herrado con hierro candente, desapareciendo otros sistemas como las muescas en las orejas o el empleo de pez (Hathaway, 2006: 68-80)2.

Se puede afirmar que es obvio, que el tipo de códigos y marcas de propiedad pecuarias, objeto de este estudio, constituyen uno más de los elementos del conjunto de técnicas y tradiciones de la cultura pastoril tradicional en vías de desaparición. En gran medida, su pérdida se está debiendo a la disminución drástica de las explotaciones ganaderas en el Pirineo y del número de cabezas de ganado en particular en el Valle de Roncal. Por otro lado, su abandono como técnica dentro del manejo de los animales también se entiende por la entrada de nuevos procesos de identificación administrativa de los semovientes: crotales, chips, etc. Es en este momento cuando muchos de estos viejos ideogramas se han convertido para los habitantes roncaleses más jóvenes en verdaderos jeroglíficos indescifrables. Quedan así reunidos en un conjunto que Palombo (1998) denomina marcas desconocidas. Un término empleado en Argentina para designar a aquellas viejas señales que ya no respondían a ningún propietario identificable y que se habían perdido en la memoria de los legajos y documentos de archivo. De igual manera han comenzado a dormir muchas de estas señales roncalesas y sólo perduran vivas en la memoria colectiva de los más mayores de la citada comarca.
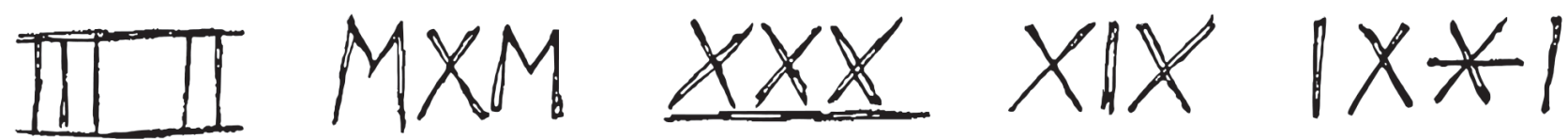

Fig. 31. Ejemplos de marcas de almadías. / Examples of almadias markings. Fuente: Guerrero, 1992.

\footnotetext{
2 Sobre el tatuaje en las orejas del ovino español ver; Sánchez Belda (1981: 228-229)
} 


\section{AGRADECIMIENTOS}

Este estudio hubiera sido imposible de realizar sin la inestimable ayuda de diferentes enlaces locales que pudieron no sólo poner al equipo en contacto con las casas ganaderas del valle sino también actuar como encuestadores en la labor de trabajo de campo. Hay que destacar así, de norte a sur, la ayuda de Pedro Antonio Orduna y Carlos Orduna en Uztarroze -quien además nos ha ayudado con el material fotográfico y su arreglo de estudio-; de Maitane Bake en Izaba, Marcelino Landa en Urzainki, Martín Javier Rípodas Trigo, Joaquín Anaut y Miguel González Glaría en Garde; José Ignacio Riezu Boj en Erronkari; Jabi Petrotx e Iñaki Ayerra en Burgi y de los hermanos José Luis y Teodoro Sanz Sanz en Bidankoze. Y si a ellos es necesario agradecer su labor, de obligado cumplimiento es reconocer el tiempo invertido y la riqueza de datos aportados por todos aquellos informantes encuestados en cada una de las siete villas roncalesas donde se desarrolla el presente trabajo. También querríamos dar las gracias a Javier González Díaz, Agente de Extensión Agraria del Cabildo de La Palma (Canarias). Este estudioso de la cultura agropecuaria isleña nos ha facilitado una interesante bibliografía relativa al marcaje de ganado en ese contexto. Referencias que, juntamente con otras de diversas regiones, aportan una visión comparada del carácter etnográfico de esta técnica de manejo ganadero. Finalmente señalar la labor desinteresada del ilustrador Javier Álvarez Vidaurre que perfiló los vectores de figuras correspondientes a las marcas de cada casa. Eskarrik anitx oroer.

\section{BIBLIOGRAFÍA}

Aragón Ruano, A., 2015. Relaciones ganaderas entre Navarra y Guipúzcoa durante la Baja Edad Media y el comienzo de la Edad Moderna. En la España medieval 38, 13-35.

Aragón Ruano, A., 2018. Discursos de frontera, facerías y libertad de comercio en el Pirineo navarro durante la Edad Moderna. Príncipe de Viana 272, 1131-1146.

Aragon, R., 2018. La trashumance ovine dans les Pyrennes. Pratique ancestrale et solution d'avenir. Aspects zootechniques et sanitaires. Ecole Nationale Vétérinaire, Toulouse.

Ariznabarreta, A., 1991. La marca ganadera y su utilización como signo de vinculación entre la casa y su sepultura (EI Pueyo de Jaca. Valle de Tena). Kobie 5, 139-147.

Barandiarán, J. M. et al. 2000. Ganadería y pastoreo en Vasconia. Atlas Etnográfico de Vasconia. Etniker, Bilbao.

Blot, J., 1984. Artezainak: Les Bergers basques. Elkar, Donostia.

Buisan, G., 2006. Des cabanes et des hommes. Vie pastorale dans les Pyrénées. Cairn, Pau.

Butzer, K. W., 1988. Cattle and Sheep from Old to New Spain: Historical Antecedents. Annals of the Association of American Geographers 78, 29-56. https://doi.org/10.1111/j.1467-8306.1988.tb00190.x.

Campello, F., Péquignot, N., 2021. Les pratiques et savoir-faire de la transhumance en Franc. Inventaire du Patrimoine Culturel Im- matériel. Nº de la fiche: 2020_67717_INV_PCI_FRANCE_00469. https://www.culture.gouv.fr/Media/Medias-creation-rapide/Lespratiques-et-savoir-faire-de-la-transhumance-en-France.pdf

Casaurang, J., 2002. Pasteurs et paysans béarnais: abris, cabanes, maisons. Cairn, Pau.

Cavaillès, H., 2003. La Transhumance pyrénéenne et la circulation des troupeaux dans les plaines de Gascogne. Aubagne d'Ardèche.

Comas, D. 2015. Piriniotarrak: temas de cultura pirenaica. Pirinioetako kultura. Etor-Ostoa, Lasarte-Oria.

Cordón, J. 1987. El marcado del ganado monchino en la sierra de Betayo (Trucíos-Vizcaya). En: AA.VV., Homenaje al Dr. José María Basabe, 114-121. Vol. 2. Eusko Ikaskuntza, Donostia.

Cunchinabe, D., 2013. Paysages et marqueurs spatiaux hérités des parcours pastoraux: du "borde-bordar" " au cayolar". L'empreinte du "système maison" en Soule. [Rapport de recherche] ITEM, EA 3002, Université de Pau et des Pays de l'Adour, Pau. https://halshs.archives-ouvertes.fr/halshs-01110566

Dabadie, S., Etchezaharreta, C., 2017. Euskal Artzainak. Bi munduren artean. Bergers basques. Entre deux mondes. Elkarlanean, Baiona.

Estornés, B., 1930. Artistas anónimos: nuestros pastores. Sus objetos usuales. La talla y decoración de la madera especialmente la de boj. Motivos decorativos. RIEV 21(2), 403-430.

Fernández de Larrinoa, K., 2009. Pastoreo en Sola: de la trashumancia a los pastos de altitud y a las queserías en el fondo del valle. Ager 8, 25-44.

Fillat, F., 2008. Pastos del Pirineo. CSIC, Madrid.

García, J., Lastana, T., 2018.El Pirineo aragonés como paisaje cultural. Pirineos 173, 54-97.

González Díaz, A., 2014. Cáscaras y empleitas. La cultura quesera tradicional en la isla de La Palma. Cartas Diferentes, Breña Alta.

González Solís, E., 2018. "Mucho más que la Mesta". Rebaños, pastos y economía rural en Extremadura en el siglo XVIII. UCM, Madrid.

Guerrero, C., 1992. Estudio de las almadías en sus diversos aspectos históricos, geográficos y culturales. CEEN 92, 7-24.

Hathaway, S., 2006. Manuel. Bonnes pratiques pour l'Industrie de la viande. FAO. Foundation International Carrefour. Roma.

Hernández, Fco., Rodríguez, M., 2000. Las marcas en las cabras de Lanzarote. Lancelot 860, 64-65.

Labeaga, J., 1992. Almadías en Navarra. Merindad de Sangüesa. Gobierno de Navarra, Pamplona.

Landais, E., 2000. Le marquage du bétail dans les systèmes pastoraux traditionnels. Revue Élev. Méd. vét. Pays trop. 53, 349-363.

Le Couédic, M., 2010. Les pratiques pastorales d'altitude dans une perspective ethnoarchéologique. Cabanes, troupeaux et territoires pastoraux pyrénéens dans la longue +durée. Sciences de l'Homme et Société. Université François Rabelais, Tours. https://tel.archives-ouvertes.fr/tel-00543218v2

Leizaola, F., 1977. Euskalerriko Artzaiak. Etor. Donostia.

Leizaola, F., 1991. El pastoreo tradicional en Gipuzkoa: notas para su estudio. Narria: Estudios de artes y costumbres populares 55-56, 16-26. 
Leizaola, F., 1978. Cultura Pastoril. In J. M. de Barandiarán (ed.), Euskaldunak. La etnia vasca, 65-96. Vol. 1. Etor, Donostia.

Lorenzo, M., 2002. El pastoreo en El Hierro. La manada de ovejas. Cabildo Insular de El Hierro, Santa Cruz de Tenerife.

Mateo, M., Orduna, P., 2017. Construcciones de uso ganadero en las Bardenas Reales de Navarra: corrales y barreras. CEEN 91, 139-186.

Mesa, J., 2004. Las marcas de ganado en Tenerife: una aproximación histórica. El Pajar18, 37-48.

Orduna, C., Orduna, P., 2019. Altxunbidëa. Estudio etnofotográfico del ciclo anual trashumante roncalés. CEEN 93, 143-194.

Orduna, P., 2011. Vecindad y derecho consuetudinario: análisis de los usos y costumbres comunitarias en el Valle de Roncal. CEEN 86, 147-203.

Orduna, P., 2014. Aproximación etnohistórica al trabajo de la pez en las Bardenas Reales (Navarra). Revista de Dialectología y Tradiciones Populares 2, 413-433.

Pallaruelo, S., 1988. Pastores del Pirineo. Ministerio de Cultura, [s.l.].

Palombo, G., 1998. Los signos del dominio del ganado (marcas y señales) en el derecho rural argentino. Revista de Historia del Derecho26, 321-378.

Pérez, L., 2009. Sistemas tradicionales de identificación y clasificación de la cabra palmera. Universidad de La Laguna, La Laguna.

Sabaté, F., 2008. Las fuentes orales en los estudios de agroecología. El caso del agrosistema de Ycode (Tenerife). Cabildo de Tenerife, Tenerife.
Sáinz, Mª 2000., Etnografía histórica de Mendavia (III): la ganadería. CEEN 75, 179-200.

Sánchez Belda, A., 1981. Identificación animal. Ministerio de Agricultura, Publicaciones de Extensión Agraria, Madrid.

Sánchez, G., Rodríguez, M. 2014.Medida de similaridad entre imágenes de marcas de ganado mediante distribuciones de forma. Revista Ingenierías Universidad de Medellín 13(25), 177-189.

Sardaña, J., René, R., 2009. Señales y marcas de propiedad del ganado en el Valle de Broto (Huesca). Geórgica 13, 39-61.

Suárez, F., 2019. Historia y tradición ganadera en el oeste de Gran Canaria. Mercurio, Madrid.

Vacas, P., 2019. El Pastor: comunicación, saberes y biodiversidad. UCM, Madrid.

Vargas, I., 2012. La entrevista en la investigación cualitativa: nuevas tendencias y retos. Calidad en la Educación Superior 3(1), 119-139.

Violant i Simorra, R., 1997. El Pirineo español. Alta Fulla, Barcelona.

\section{Fuentes documentales de archivo}

Archivo Municipal de Vidángoz. Caja 009 - Correspondencia. 1940 y Libro de registro especial de ganado (1954-1963).

Archivo Municipal de Isaba. Libros de registro especial de ganado (1947-1970). 
